\title{
Online Optimal Variable Charge-Rate Coordination of Plug-In Electric Vehicles to Maximize Customer Satisfaction and Improve Grid Performance
}

\author{
Somayeh Hajforoosh, Mohammad A.S. Masoum and Syed M. Islam \\ Department of Electrical and Computer Engineering, Curtin University of Technology, Perth, WA, Australia. \\ Somayeh.hajforoosh@postgrad.curtin.edu.au,m.masoum@curtin.edu.au and s.islam@curtin.edu.au
}

Abstract- Participation of plug-in electric vehicles (PEVs) is expected to grow in emerging smart grids. A strategy to overcome potential grid overloading caused by large penetrations of PEVs is to optimize their battery charge-rates to fully explore grid capacity and maximize the customer satisfaction for all PEV owners. This paper proposes an online dynamically optimized algorithm for optimal variable charge-rate scheduling of PEVs based on coordinated aggregated particle swarm optimization (CAPSO). The online algorithm is updated at regular intervals of $\Delta \mathrm{t}=5 \mathrm{~min}$ to maximize the customers' satisfactions for all PEV owners based on their requested plug-out times, requested battery state of charges $\left(S O C_{R e q}\right)$ and willingness to pay the higher charging energy prices. The algorithm also ensures that the distribution transformer is not overloaded while grid losses and node voltage deviations are minimized. Simulation results for uncoordinated PEV charging as well as CAPSO with fixed charge-rate coordination (FCC) and variable charge-rate coordination (VCC) strategies are compared for a 449-node network with different levels of PEV penetrations. The key contributions are optimal VCC of PEVs considering battery modeling, chargers' efficiencies and customer satisfaction based on requested plug-out times, driving pattern, desired final SOCs and their interest to pay for energy at a higher rate.

Index Terms- Electric vehicle charging coordination, customer satisfaction, variable charging, coordinated aggregated PSO, smart grid. 
Index:

$\begin{array}{ll}i, j & \text { Counters } \\ m & \text { Node number } \\ n & \text { Total number of nodes }\end{array}$

Parameters:

$S O C_{\text {initial }}(i) \quad$ State of charge of the $i^{\text {th }} \mathrm{PEV}$ at plug-in time (\%)

$S O C_{\operatorname{Re} q}(i) \quad$ Requested SOC of the $i^{\text {th }} \operatorname{PEV~(\% )~}$

$N_{P E V}\left(\Delta t_{k}\right) \quad$ Number of available PEVs for current time slot

$T_{R e q}(i) \quad$ Plug-out time of the $i^{\text {th }} \mathrm{PEV}$ (hour)

$\operatorname{Bid}\left(\Delta t_{k}, i\right) \quad$ The price that the $i^{\text {th }} \mathrm{PEV}$ owner is willing to pay at current time slot $(\$ / \mathrm{kWh})$

$\operatorname{Bid}_{\text {Max }}\left(\Delta t_{k}\right) \quad$ Maximum offered bid by all existing PEVs at current time slot $(\$ / \mathrm{kWh})$

$R_{m, m+1}$

Resistance of the line segment between nodes $m$ and $m+1$ (ohm)

$Y_{m, m+1}$

Admittance of the line segment between nodes $m$ and $m+1$ (ohm)

$V_{o c, i}$

Open circuit voltage for $i^{\text {th }}$ node (V)

$R_{i}$

Battery equivalent internal resistance for the $i^{\text {th }}$ node (ohm)

$I_{i}^{\text {Rated }}$

Rated charger current for the $i^{\text {th }} \mathrm{PEV}$ (A)

$Q_{i}$

Rated battery ampere hour for the $i^{\text {th }}$ PEV (Ah)

$C R_{i}^{\max }$

Maximum charging rate for the $i^{\text {th }} \mathrm{PEV}$ (A)

$\eta_{c h}\left(C R_{i}^{b e s t}\left(\Delta t_{k}\right)\right)$

Charger efficiency for the $i^{\text {th }} \mathrm{PEV}$ at the best charge-rate (\%)

$V_{\min }$ and $V_{\max }$

Lower and upper node voltage limits (per unit; p.u.)

$D_{\max }\left(\Delta t_{k}\right)$

Maximum demand level that would normally occur without any PEVs during a day where selected to be $0.84 \mathrm{MW}$ corresponding to the maximum load for the selected $D L C$ (MW)

$\mathrm{C}$

Ratio of charging or discharging current in A to the capacity of battery in Ah

$L_{j}$

Trip path for $j^{\text {th }} \mathrm{PEV}(\mathrm{km})$

$L_{i}^{\max }$

Rated length path that each type of PEVs can trip $(\mathrm{km})$

$\alpha_{D}, \alpha_{V 1}$ and $\alpha_{V 2}$

Coefficients used to adjust the slopes of the penalty functions

$k_{1}, k_{2}, k_{3}$

Coefficients used to adjust the objective function based on the priority

Variables:

$F V\left(\Delta t_{k}\right) \quad$ Penalty function for node voltage at current time slot

$F D\left(\Delta t_{k}\right) \quad$ Penalty function for demand (distribution transformer loading) at current time slot

$\operatorname{SOC}\left(\Delta t_{k}, i\right) \quad$ State of charge of the $i^{\text {th }} \mathrm{PEV}$ at $k^{\text {th }}$ time slot $(\%)$

$T_{\text {Remain }}\left(\Delta t_{k}, i\right) \quad$ The remaining available time for charging the $i^{\text {th }}$ PEV at current time slot (hour)

$C_{S}\left(\Delta t_{k}, i\right) \quad$ Customer satisfaction level for current time slot at $i^{\text {th }}$ node (\%)

$C_{S}\left(\Delta t_{k+1}, i\right) \quad$ Customer satisfaction level for next time slot at $i^{\text {th }}$ node (\%)

$V_{i} \quad$ Terminal voltage for $i^{\text {th }}$ node (per unit; p.u.)

$I\left(\Delta t_{k}, i\right) \quad$ Charging current for the $i^{\text {th }} \mathrm{PEV}$ at current time slot (A)

$C R_{i}^{\text {best }}\left(\Delta t_{k}\right) \quad$ Optimized charging rate for the $i^{\text {th }} \mathrm{PEV}$ at current time slot (A)

Dt $\left(\Delta t_{k}\right) \quad$ Total load at current time slot (MW)

$D L\left(\Delta t_{k}\right) \quad$ Daily load at current time slot (MW)

$\operatorname{PLoad}\left(\Delta t_{k}\right) \quad$ Base-load power at current time slot (MW)

$P_{P E V, i}\left(\Delta t_{k}\right) \quad$ Consumed power for the $i^{\text {th }} \mathrm{PEV}(\mathrm{KW})$ 


\section{INTRODUCTION}

High-Tech developments in the automotive technology, growing environmental concerns in oil prices have triggered the advent of plug in electrical vehicles (PEVs). However, large fleets of PEV charging will require additional electric power demand that may lead to undesirable peaks in power consumption, transformer overloading, and interruptions. A potential solution is using online and/or offline PEV charging coordination strategies [1-4]. Ref. [3] proposes real-time PEV coordinated charging in residential distribution systems to reduce costs of power generation and losses. Ref. [4] presents real-time PEV charging/discharging coordination without considering customer preferences and variable charge-rates.

Ref. [5] proposes an online auction protocol such that vehicle owners use agents to bid for the charging opportunities. However, all PEVs have the same fixed charge-rate which is not usually the case in practical applications as vehicles have different battery and charger types, and ratings. Ref. [6] presents online coordination of PEV charging and discharging in a small geographic area based on the unrealistic assumption that no PEVs will arrive when a charging schedule is made. Ref. [7] analyzes the performance of optimal PEV charging coordination including customer satisfaction without considering variable charge-rates. Refs. [8-9] focus on maximizing aggregator revenue without carefully addressing customers' preferences and may not necessarily lead to maximum benefit for customers. Alonso et al. [10] designed the PEV scheduling to fill the valleys of the residential load profile during periods of lower load demands to avoid vehicle charging during peak load hours using a genetic algorithm. In addition, Nguyen and Le [11] presented an optimization problem that aims to minimize the total cost of energy of each PEV user. This work considers time-varying electricity prices and performs daily scheduling. Also, a real-time scheduling method of PEV charging loads is proposed in [12] to increase voltage security margin in a low-voltage distribution system. A strategy is proposed in [13] to mitigate the adverse impacts that uncontrolled charging of the PEVs impose on the host power system. However, [10-13] don't include variable charging rates and ignore battery and charger efficiencies. Ref. [14] assumes that electric vehicles drivers are insensitive to charging costs and discharging benefits. In addition, in [15], the PEV charging and wind power scheduling were integrated.

In [26], a cost minimizing strategy benefiting is proposed, but does not consider fairness in charging for all PEVs. A realtime charging coordination of PEVs based on hybrid fuzzy discrete particle swarm optimization (PSO) was presented in [27]. In addition, in [28] a multi-agent system that coordinates EV charging in distribution networks has been proposed using a distributed control method. A multi-objective scheduling strategy is formulated to charge a number of PEVs while a fuzzy solution is proposed to achieve the best compromise between the two objective functions in [29]. Moreover, Ref [30] used the population-based metaheuristics approach to solve the optimization problems. Another study [31] also shows that optimizing the charging schedule can reduce grid voltage drops and power losses as well as optimizing the load profiles.

In performing PEVs charging coordination considering customer satisfaction, some vehicles can submit requested plug-out times along with the associated requested state of charges $\left(S O C_{R e q}\right)$. Meeting these requirements is not a big problem when all the vehicles plug-out at their requested departure times. However, when unexpected departures of PEVs occur, the conventional schemes such as those proposed in [3-6], may not be able to provide acceptable levels of satisfaction fairness 
among the users. Moreover, some vehicles may not be fully charged at the end of charging horizon. The problem can be resolved by using variable charging rates as a strategy to adapt the power drawn by the charger from the grid to the load, in order to fully exploit grid capability and provide a high degree of user satisfaction.

While the objective functions of [14-15] are optimization of aggregators' income and the cost of energy without addressing customers' satisfactions. In [16], the variable-based charging of PEVs is investigated; however, requested plug-out times and customers' preferences are not considered.

The main objective of this paper is to perform optimal PEV charging coordination to maximize all customers' satisfactions without exceeding grid constraints. This is done by $i$ ) allowing customers to specify their own charging demands including requested plug-out times, desired departure SOCs and the higher electricity prices they are willing to pay, ii) developing an optimization problem where the decision variables are the charging rates updated at time slots of $\Delta \mathrm{t}=5 \mathrm{~min}$, and iii) solving the problem using coordinated aggregated particle swarm optimization (CAPSO). We rely on the quality and speed of the CAPSO solution for accurate and quick online PEV charging [24], [34-35]. Among the artificial intelligent based algorithms, the CAPSO is known to achieve near optimal solutions with better convergence characteristics. Simulation results for uncoordinated PEV charging, as well as CAPSO with fixed charge-rate coordination (FCC) and variable chargerate coordination (VCC) are compared for a 449-node network. The proposed algorithm takes into consideration random plug-in times, initial SOCs, requested plug-out times, requested final SOCs and maximum charging rates of PEV batteries.

\section{MODELING OF BATTERY AND CHARger FOR PEVS}

Coordination of PEVs in smart grid requires accurate modeling of its battery profile and charging characteristics. Many modern battery chargers are capable of achieving high efficiency values; however, their charging efficiencies indicate significant dependency on the charging rate due to the internal battery resistance [19-21]. This is particularly important in calculating the actual stored energies and SOCs at different times during the charging period. Fig.1 (a) shows a sample experimental data of the average charging efficiency as a function of the charging rate [17]. In this paper, vehicle batteries are modelled in the steady state mode. The details of the selected model (designed by Idaho National Laboratory) are presented in [32-33].

Only a few studies have considered the power losses in the vehicle battery charging procedure by assuming a constant efficiency for the energy transfer from the grid to the battery $[2,9,18]$. In this study, for accurate implementation and evaluation of PEV variable charging coordination, battery model and dependency of charging efficiency on the charging rate are taken into account. In addition, the equivalent circuit of Fig.1 (b) is used to include the impact of battery internal resistance in SOC calculation of Section III.

\section{Problem Formulation}

The objective of this study is focused on a scenario with multiple PEV owners that have different preferences and will schedule their charging profiles over time slots of $\Delta t=5 \mathrm{~min}$ to maximize the customer satisfaction for all PEVs at the next 
time slot while avoiding grid constrains. The proposed charging approach will ensure fairness in the SOC distribution at each time slot for all PEVs. Furthermore, if a PEV owner decides to leave prior to his/her initially requested departure time, the vehicle will receive a reasonable level of SOC. This is an improvement compared to the fix charging based methods [27] where PEVs may not receive any charging services if they are plugged-out before the designated times. Therefore, the comprehensive nonlinear objective function of Eq.1 is defined to maximize the total customer satisfaction by optimizing the PEVs' charging rates at each time slot:

$$
\begin{aligned}
& \operatorname{Max}\left(F(t)=\sum_{i=1}^{N_{P E V}} w_{i}\left(\Delta t_{k}\right)\left(C_{s}\left(\Delta t_{k+1}, i\right)-C_{s}\left(\Delta t_{k}, i\right)\right)\right. \\
& \text { for } i=1, \ldots, N_{P E V}\left(\Delta t_{k}\right) \quad, t_{k}=\Delta t_{k}, 2 \Delta t_{k} \ldots, 24 \text { hours } \\
& \text { where } w_{i}\left(\Delta t_{k}\right)=k_{1}\left[1-\frac{\operatorname{SOC}\left(\Delta t_{k}, i\right)}{\operatorname{SOC}_{\mathrm{Req}}(i)}\right]+k_{2}\left[1-\frac{T_{\text {Remain }}\left(\Delta t_{k}, i\right)}{T_{\text {Req }}(i)}\right]+k_{3} \frac{\operatorname{Bid}\left(\Delta t_{k}, i\right)}{\operatorname{Bid}_{\text {Max }}\left(\Delta t_{k}\right)} \\
& C_{S}\left(\Delta t_{k}, i\right)=\frac{\operatorname{SOC}\left(\Delta t_{k}, i\right)-S O C_{\text {initial }}(i)}{S O C_{\mathrm{Req}}(i)-S O C_{\text {initial }}(i)}
\end{aligned}
$$

In Eq.2, $w_{i}\left(\Delta t_{k}\right)$ is the weighting factor that includes the customers' preferences and their enthusiasm to pay higher energy prices at each time slot. For example, if there is a vehicle with lower initial SOC and less remaining charging time, but the PEV owner prefers to pay a price higher than others, then the PEV will receive more power at that time slot.

To calculate SOC for the next time slot $\operatorname{SOC}\left(\Delta t_{k+1}, i\right)$ there are different techniques in $[21,37-40]$, this paper adopts the battery equivalent circuit model of [21] consisting of a constant voltage source in series with a constant resistance as shown in Fig.1b. This model is represented as:

$$
\begin{aligned}
& V_{i}\left(\Delta t_{k}\right)=V_{o c, i}+R_{i} I\left(\Delta t_{k}, i\right) \\
& I\left(\Delta t_{k}, i\right)=C R_{i}^{\text {best }}\left(\Delta t_{k}, i\right) \times I^{\text {Rated }}(i)
\end{aligned}
$$

The $\operatorname{SOC}\left(\Delta t_{k+1}, i\right)$ can be formulated based on the charging current as follows:

$$
\operatorname{SOC}\left(\Delta t_{k+1}, i\right)=\operatorname{SOC}\left(\Delta t_{k}, i\right)+\left(\frac{\Delta t}{Q_{i}} I\left(\Delta t_{k}, i\right) \times \Upsilon\right) \times 100
$$

where, $\Upsilon$ is the status of each PEV where digits " 1 " and "0" correspond to the PEV being connected or not connected. The power delivered to PEV during the charging process is:

$$
\begin{aligned}
P_{P E V}^{\text {Delivered }} & \left(\Delta t_{k}, i\right)=V_{o c}(i) \times I\left(\Delta t_{k}, i\right)+R_{i} I^{2}\left(\Delta t_{k}, i\right) \\
& =V_{o c}(i) \times C R_{i}^{\text {best }}\left(\Delta t_{k}, i\right) \times I^{\text {Rated }}(i)+R_{i}\left(C R_{i}^{\text {best }}\left(\Delta t_{k}, i\right) \times I^{\text {Rated }}(i)\right)^{2}
\end{aligned}
$$

and the power consumed by the $i^{\text {th }} \mathrm{PEV}$ from grid considering the impact of charger's efficiency is:

$$
\begin{aligned}
& P_{P E V}^{\text {Consumed }}\left(\Delta t_{k}, i\right)=P_{P E V}^{\text {Delivered }}\left(\Delta t_{k}, i\right) / \eta_{c h}\left(C R_{i}\left(\Delta t_{k}\right)\right) \\
& P_{P E V}^{\text {Consumed }}\left(\Delta t_{k}, i\right) \times \eta_{c h}\left(C R_{i}\left(\Delta t_{k}\right)=V_{o c}(i) \times C R_{i}^{\text {best }}\left(\Delta t_{k}, i\right) \times I^{\text {Rated }}(i)+R_{i}\left(C R_{i}^{\text {best }}\left(\Delta t_{k}, i\right) \times I^{\text {Rated }}(i)\right)^{2}\right.
\end{aligned}
$$

The charging current can be calculated from (7A) as follows: 
$I\left(\Delta t_{k}, i\right)=\frac{\sqrt{4 \times \Delta t \times R_{i} \times P_{P E V}^{\text {Consumed }}\left(\Delta t_{k}, i\right) \times \eta_{c h}\left(C R_{i}^{\text {best }}\left(\Delta t_{k}\right)\right)+V_{o c, i}^{2}}-V_{o c, i}}{2 R_{i} \times C R_{i}^{\text {best }}\left(\Delta t_{k}, i\right)}$

Substituting Eq.8 into Eq.6 yields:

$\operatorname{SOC}\left(\Delta t_{k+1}, i\right)=\operatorname{SOC}\left(\Delta t_{k}, i\right)+\left(\frac{\Delta t \times \sqrt{4 \times \Delta t \times R_{i} \times P_{P E V}^{\text {Consumed }}\left(\Delta t_{k}, i\right) \times \eta_{c h}\left(C R_{i}^{\text {best }}\left(\Delta t_{k}\right)\right)+V_{o c, i}^{2}}-V_{o c, i}}{2 R_{i} \times C R_{i}^{\text {best }}\left(\Delta t_{k}, i\right) \times Q i} \times \Upsilon\right) \times 100$

A numerical example for the calculation of SOC (based on Eqs. 6-9) is provided in the Appendix.

\subsection{ASSUMPTIONS AND DEFINITIONS}

- PEVs can be connected/disconnected at any time according to the customer's needs. Customers will input their requested plug-out times and requested final SOCs at the time of plug-in. They are willing to pay higher fees compared with the short term market energy price (MEP, Fig.2(a)) for their requested special charging arrangements.

- Each hour is divided into 12 time slots of $\Delta t=5$ minutes.

- The aggregator is assumed to know the available charging power during each time slot. Each PEV can be charged after plug-in with a variable charge-rate at each time slot, and expects to reach a desired $S O C_{R e q}$ by requested plug-out time.

- The aggregator has access to PEV information using smart metering technology including their locations, charger types, battery sizes, and plug-in time.

- At each time slot, the status of each PEV will be updated. This is not a given parameter and each PEV will send a plugin signal when it's being randomly connected to the grid.

- Fig.2(b) shows the spectrums of the random plug-in times and requested plug-out times of the PEVs.

- A PEV-Queue Table will be generated to keep track of vehicles' status including their plugged-in times; requested and actual plugged-out times; initial SOCs; requested and actual SOCs; charger type and battery sizes. As a result, after plugging a new PEV at $\Delta t_{k}$, the Table will be updated and the implemented CAPSO coordination algorithm will be executed to obtain a new optimal online charging schedule.

- PEV chargers are controllable and have variable charging functions. During the charging process, each PEV is assumed as a variable active load.

- The requested time $T_{R e q}(i)$ for each PEV must be greater than the minimum charging time $T_{\min }(i)$ required to charge the battery which depends on the maximum allowed charge-rate.

where, $\mathrm{T}_{\min }(\mathrm{i})=\frac{\operatorname{SOC}_{\mathrm{Req}}(i)-\operatorname{SOC}_{\text {initial }}(i)}{\text { Charger }_{\text {Size }}(i)}$

- The proposed coordination process is updated when a new vehicle is plugged-in or an existing one plugs out, or a time slot has passed periodically.

- In order to make the system more robust and improve customer satisfaction, PEVs are allowed to be disconnected before their requested plug-out times. This will considerably complicate the coordination algorithm. 


\subsection{Constraints}

In this paper the objective function (Eq.1) is subjected to the following constraints at each time slot to preserve power quality of the grid while supplying base and PEV loads:

$$
\begin{aligned}
& V_{\min } \leq V_{j}\left(\Delta t_{k}\right) \leq V_{\max }, \text { for } j=1, \ldots, N_{\text {node }} \\
& D_{t}\left(\Delta t_{k}\right)=\sum_{k=1}^{n} P_{k}\left(\Delta t_{k}\right)=\sum_{k=1}^{n}\left(P_{\text {load }_{k}}\left(\Delta t_{k}\right)+P_{P E V, i}\left(\Delta t_{k}\right)\right) \leq D_{\max }\left(\Delta t_{k}\right) \\
& D_{\max }\left(\Delta t_{k}\right)=\operatorname{Max}\left\{D L\left(\Delta t_{1}\right), D L\left(\Delta t_{2}\right), \ldots, D L\left(\Delta t_{k}\right)\right\}, K=1, \ldots, 288
\end{aligned}
$$

To sustain battery health, its SOC level should be kept within a certain range recommended by the manufacturer. Therefore, the following SOC constraint is included:

$$
\operatorname{SOC}_{\text {initial }}(i) \leq \operatorname{SOC}\left(\Delta t_{k}, i\right) \leq \operatorname{SOC}_{\mathrm{Re} q}(i), \text { fori }=1, \ldots, N_{P E V}\left(\Delta t_{k}\right)
$$

Once $\operatorname{SOC}\left(\Delta t_{k}, i\right)$ reaches $S O C_{R e q}(i)$, the $i^{\text {th }}$ battery charger will be switched to a standby mode.

The charge and discharge rates are often represented as $C$ or $C$-rate, which is a measure of the rate at which a battery is charged or discharged relative to the total capacity of the battery. The $C$-rate is given by the numerical value of the ratio of the charging or discharging current in A to the total capacity of the battery in Ah. In this paper, the variable charging rates are considered to be from $0 C$ to $C R_{i}^{\max }=1 C$ while $10 \%$ of vehicles are assumed to have fast charging facilities with charge rates of up to $C R_{i}^{\max }=2 C$. A random generator is used to generate the charge rates. The PEV charge-rates will be limited as follows:

$0 \leq C R_{i} \leq C R_{i}^{\max } \quad C R_{i} \in \mathfrak{R} \quad i=1, \ldots, N_{P E V}\left(\Delta t_{k}\right)$

\subsection{Simulated input data}

The continuous uniform random number generator is used to simulate the random plug-in times and expected plug-out times (Fig. 2(b)), as well as the requested SOCs. The initial state of charge $S O C_{\text {initial }}(\%)$ for each PEV is calculated based on its trip length, as follows (Eq.16) [22]:

$$
\begin{aligned}
& \operatorname{SOC}_{\text {initial }}=\left\{\begin{array}{lr}
\alpha_{\mathrm{i}}-\left(\alpha_{i}-\beta_{i}\right) \times \frac{L_{j}}{L_{i}^{\text {max }}} & \text { for } L_{j} \leq L_{i}^{\max } \\
\beta_{i} & \text { otherwise }
\end{array}\right. \\
& \text { for } i=1, \ldots, N_{\text {typeof } P E V S}, j=1, \ldots, N_{P E V}\left(\Delta \mathrm{t}_{\mathrm{k}}\right)
\end{aligned}
$$

where $i$ indicates the type of PEVs, $j$ is the number of PEVs. In addition, three types of PEVs including Volkswagen e-golf (Type 1), Honda Fit (Type 2) and Ford C-Max (Type 3) with chargers' rates of 7.2, 6.6, and $3.3 \mathrm{~kW}$ that correspond to battery sizes of 24, 20, and 7.6 kWh are considered [23]. The selected values for parameters $\alpha_{1}, \alpha_{2}$ and $\alpha_{3}$, are $0.85,0.8$ and $0.75 ; \beta_{1}, \beta_{2}$ and $\beta_{3}$ are $0.15,0.2$ and 0.25 ; and $L_{1}, L_{2}$ and $L_{3}$ are 40,50 and 60 miles, respectively. 


\section{Proposed Online Heuristic Based Coordination Algorithm For PeV Charging}

PSO algorithms differ in the way the swarm is updated in the feasible search space. The CAPSO approach has been applied to solve many steady state optimization problems related to power network [24]. In CAPSO, each particle updates its position by only considering the positions of particles with better achievements. Thus, this paper applies a coordinated aggregation-based PSO (CAPSO) algorithm to capture the best solutions for the PEV coordination problem (Eqs.1-15). The developed CAPSO algorithm is similar to the algorithm developed in [25] for economic load dispatching with the main difference of a proposed updating approach for the velocity vector.

\subsection{Proposed Initial Population and Structure of Particles:}

The selected particles for variable charge-rate online PEV coordination contain the charging rates $C R_{i}\left(\Delta t_{k}\right)$ for each PEV at $\Delta t_{k}$ that are limited between 0 and $2 \mathrm{C}$, as follows (Eq.17):

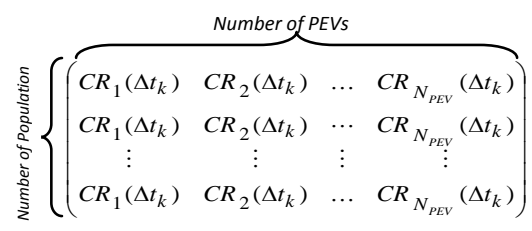

\subsection{CAPSO Fitness Function}

To improve quality of CAPSO solutions fitness functions are used for the objective and constraints (Eqs.1-15). The inverse algebraic products (Eq.18) of the proposed penalty functions for voltage (Eqs.19-20) and demand (Eq.21) are used as the fitness function to combine the PEV coordination objective function (Eq.1) and constraints (Eqs.11-15):

$$
\begin{aligned}
& F_{\text {fitmess }}\left(\Delta t_{k}\right)=\frac{F\left(\Delta t_{k}\right)}{F_{V}\left(\Delta t_{k}\right) \times F_{D}\left(\Delta t_{k}\right)} \\
& F_{V}\left(\Delta t_{k}\right)=\prod_{k=1}^{n} F_{V, k}\left(\Delta t_{k}\right) \\
& F_{V, k}(t)= \begin{cases}e^{\alpha_{V}\left(1-V_{k}(t)\right)} & V_{k}(t) \leq V_{\min } \\
1 & V_{\text {min }} \leq V_{k}(t) \leq V_{\text {max }} \\
e^{\alpha_{V_{2}\left(V_{k}(t)-1\right)}} & V_{k}(t) \geq V_{\max }\end{cases} \\
& F_{D}\left(\Delta t_{k}\right)= \begin{cases}1, & D_{t}\left(\Delta t_{k}\right) \leq D_{\text {max }}\left(\Delta t_{k}\right) \\
e^{\alpha_{D}\left(D_{t}\left(\Delta t_{k}\right)-D_{\max }\left(\Delta \Delta_{k}\right)\right)}, & D_{t}\left(\Delta t_{k}\right) \geq D_{\text {max }}\left(\Delta t_{k}\right)\end{cases}
\end{aligned}
$$

\subsection{Simulation Results}

To present the effectiveness of the proposed algorithm and the impacts of considering variable charging, simulations are performed on the SG of Fig. 2(c) for the three cases of uncoordinated and CAPSO-based coordinated PEV charging with FCC and VCC using a time interval of $\Delta t=5$ minutes; PEV penetration levels of $0 \%$ (no PEVs), $16 \%, 32 \%, 47 \%$ and $63 \%$

(Fig. 2 (d)) considering $\mathrm{N}_{\text {bus }}=449, \mathrm{~N}_{\mathrm{line}}=448, \mathrm{~W}=0.73, \mathrm{C} 1=2.05, \mathrm{C} 2=2.05$, and $\mathrm{N}_{\mathrm{pop}}=100, \alpha_{\mathrm{V} 1}=\alpha_{\mathrm{V} 2}=0.3$ and $\alpha_{\mathrm{D}}=0.5$ (Eqs. 19 - 
20). Simulation results are presented in Figs. 3-6 and Tables I-II. It should be noted that the network representation in Fig.

2(c) is at the low-voltage side of each distribution transformer (DT).

To compare the performance of FCC and VCC schemes, detailed simulations will also be presented for the three selected feeders in Fig. 2(c) with the best (DT-20), moderate (DT-12) and worst (DT-14) performances. The first feeder receive $100 \%$ of customer satisfaction with both FCC and VCC, the second feeder receives $100 \%$ of customer satisfaction with VCC and the third feeder doses not receive $100 \%$ customer satisfaction regardless of the selected (FCC or VCC) coordination approach. It should be noted that DT-20 and DT-12 are not the only feeders that receive $100 \%$ of customer satisfaction with VCC. The complete lists of best feeders are DT-9, DT-13, DT-20 and DT-22 whereas the complete lists of the moderate feeders are DT-3, DT-4, DT-5, DT-7, DT-11, DT-12, DT-18 and DT-21.

In this paper, the backward-forward sweep method is used to calculate power (load) flows and bus voltages. It is assumed that the generation capacity is large enough to supply both the base and the PEV charging loads in all timeslots.

At each timeslot $(\Delta t=5$ minutes $)$, the weakest bus is defined to be the bus with the lowest voltage magnitude. The locations and voltage magnitudes of the week buses will change within the 24 hours depending on the system base load and system configuration and the PEV loadings (numbers, locations, random plug-in times and charging rates of the activated PEVs). To identify the weakest bus at each timeslot, the optimal PEV coordination is performed, the selected PEVs are activated, power flow calculation is performed, nodes are sorted based on their voltage magnitudes, and the node with lowest voltage value is selected as the weakest bus. This process is repeated for 24-hour to generate the weak voltage profiles of Figs. $3 \mathrm{c}$, $4 \mathrm{c}$ and $5 \mathrm{c}$.

\section{Case A: Uncoordinated PEV Charging}

The impact of uncoordinated PEV charging is investigated by starting the charging process as soon as vehicles are randomly plugged in. Simulation results are presented in Table I (rows 4-8) and Fig.3. As expected, the SG is facing overloading, voltage regulation and efficiency problems. For example, for $63 \% \mathrm{PEV}$ penetration, maximum power consumption has increased by about $45 \%$ (Fig.3(b)) compared to the nominal operation with no vehicles. In addition, the minimum voltage for $63 \%$ of PEVs penetration has decreased by $30 \%$ compared to its nominal value as shown in Fig.3(c). Moreover, in this case there is about $10 \%$ voltage violation for $32 \%$ PEV penetration. Furthermore, it can be seen that the voltage drops to 0.7P p.u. (Fig.3(c)), where in reality it may cause system collapse and should be limited by system operator. To overcome problems associated with uncoordinated PEV charging, the CAPSO algorithm of Section IV is adopted.

\section{Case B: Coordinated PEV Charging using CAPSO with FCC}

In this approach, the charging process of each PEV is realized at a fixed rate, corresponding to the nominal charging rate of its charger. In details, the charging process of each user starts by receiving a charging signal from charging center and will be connected till receive its required state of charge. The implemented CAPSO algorithm is used for optimal PEV charging coordination with a fix nominal charging rate. While PEV will be automatically disconnected when reaching their requested SOC levels, the consumers can also disconnect their vehicles prior to the requested plug-out times. Simulation results for 
FCC are presented in Fig.4 and Table I (rows 9-13). Compared to Case A, FCC is offering further improvements in substation transformer loading, loss power and weak bus voltages. Note that, there is still overloading of the main substation transformer.

\section{Case C: Coordinated PEV Charging using CAPSO with VCC}

Simulation results including system power consumptions and loss using CAPSO algorithm with variable charge-rate strategy are presented in Fig.5 and Table I (rows 14-18). Compared to Case B, VCC is more strictly preventing system (transformer) overloading (Fig.5(b)). It can be observed that for 63\% PEV penetration, VCC has the advantage of completing the charging process of all vehicles sooner than the FCC. However for lower PEV penetration levels of $47 \%$, $32 \%$ and $16 \%$, the two charging strategies have similar characteristics. In addition, there is no overload in system power consumption with VCC as it is limited to the designated $0.84 \mathrm{MW}$ while there is about $2.72 \%$ overloading in substation transformer using FCC (Fig. 4(b)). Moreover, the voltages are in their permissible limit and there is no problem with the voltage profiles (Fig.5(c)).

\section{DISCUSSION AND ANALYSIS}

The SOC variations within the 24 hours are presented in Figs. 6(a-d) for the best (DT-20) and the worst (DT-14) feeders:

- According to Fig.6(c) with FCC, at the worst feeder there are 4 out of 12 PEVs that are not charged at all and their initial SOCs are not changed. Therefore, the customer satisfaction at these nodes is zero which has reduced the overall satisfaction level at this feeder (DT-14).

- It is depicted that with FCC the first and the last PEV start charging times in feeder DT-14 are at 19:00pm and 4:00am, respectively; while with VCC (Fig.6(d)) some of the PEVs are started charging as early as 17:50pm and the last vehicle is being activated at 19:20pm on node "s".

- The VCC strategy is capable of fully or partially charging the PEVs that were not scheduled with FCC (e.g., were not allowed to start charging). For example with the FCC, the PEVs located on nodes $b, d$, f and h of feeder DT-14 have zero customer satisfaction (Fig.6(f)) while with the VCC their customer satisfaction rates are improved to $100 \%, 23.85 \%$, $35.94 \%$ and $23.70 \%$, respectively.

- Comparison between Figs.6(a, b) shows that all PEVs in the best feeder (DT-20) reach their requested SOCs before their requested plug-out times using VCC and all vehicles are charged by 3:40am.

- With FCC the PEV on node "l" is not activated and has not received charging service until 3:35am, while with VCC strategy the same vehicle at the same time will be fully satisfied and receives $100 \%$ of its requested SOC.

The bar charts of Fig.6 (e, f) and Table II show the amount of customer satisfaction for the best and worst feeders: 
- Using FCC, the customer satisfactions for four PEVs are zero, while with VCC all vehicles are receiving full or partial charging; Table II (rows 9-10, 18-19, 27-28). Figs.6 (g, h) show the customer satisfaction profiles for all feeders (DT-1 to DT-22) using VCC and FCC strategies:

- The numbers of feeders reaching 100\% customer satisfaction with VCC and FCC approaches are 12 and 4, while according to Table II (rows 9-10) the minimum levels of customer satisfactions in the worst feeder (DT-14) are 78\% and $64 \%$, respectively.

- The feeders have reached their requested SOC at the same time with VCC (Fig. 6(h)), while with FCC there is a significant time difference in obtaining the requested SOC even for the fully satisfied customers (Fig.6(g)). For instance, feeder DT-12 has reached 100\% customer satisfaction at time slot 110, while feeders DT-8 and DT-9 will received 100\% of customer satisfaction at time slot 130 .

Table III presents a detailed comparison between the proposed PEV coordination strategy and the three recently implemented methods ([26]-[28]). Based on rows 8-10 of Table III, the main aim and contribution of this paper which is customer satisfaction with different customer preferences using variable charging rates has not been addressed in [26-27]. In addition, this paper also presents detailed work on PEV charge optimization and analysis based on the customers' requirements that includes requested SOCs, bids and plug-out times. Furthermore, this paper is mainly focused on the variable charging strategies and uses CAPSO to achieve optimal charge rates for each time slot whereas a fix charge is considered in most of the previous studies. Finally, the impacts of charger efficiency and battery modeling have also been included in the paper which are not considered in Refs. [26] to [27].

\section{CONCLUSION}

This paper has implemented an optimal, fast and effective online variable charge-rate PEV coordination strategy using CAPSO to maximize the total customer satisfaction for all PEV owners. The proposed VCC approach will also minimize the grid losses without exceeding grid constraints based on costumers requested plug-out times, requested battery state of charges (SOCReq) and their interests to pay for higher charging energy prices at time slots of $\Delta \mathrm{t}=5 \mathrm{~min}$.

Detailed simulations results for a 449-node SG network are presented, compared and analyzed for uncoordinated PEV charging and coordinated PEV charging with FCC and VCC strategies. Main conclusions are:

- The proposed coordinated charging algorithm takes into consideration random plug-in times, initial SOCs, requested plugout times, and requested final SOCs, as well as the maximum battery charging rates, battery and charger efficiencies.

- With VCC, customers received higher levels of satisfaction, while with FCC some vehicles may not even start charging before their requested plug-out times.

- The substation transformer is not overloaded with the VCC option, while overloading conditions are noticed with FCC even at low levels of PEV penetrations of $16 \%$ and $32 \%$.

- The VCC strategy is capable of fully or partially charging the PEVs that were not scheduled with FCC. 
- The proposed charging approach (VCC) will ensure fairness in the SOC distribution at each time slot for all PEVs. Then, if a PEV owner decides to leave prior to his/her initially requested departure time, the vehicle will receive a reasonable level of SOC.

- There is no overload in system power consumption with VCC as it is limited to the designated $0.84 \mathrm{MW}$ while there is about $2.72 \%$ overloading in substation transformer using FCC .

\section{APPENDIX A: NUMERICAL EXAMPLE FOR CALCULATION OF SOC}

This appendix presents a numerical example for the calculation of SOC based on equations 6 to 9 . Assuming the battery bank voltage is $400 \mathrm{~V}$, the battery capacity is $10 \mathrm{kWh}$, and the nominal cell voltage for lithium ion batteries is $3.2 \mathrm{~V}$ then the number of cells for the whole battery bank will be 125 . It is also considered that the internal resistance for each cell is $2 \mathrm{~m} \Omega$ and then the total battery bank resistance $\mathrm{R}_{\mathrm{i}}=2 \mathrm{~m} \Omega \times 125=250 \mathrm{~m} \Omega$. In this paper, each time slot is assumed to be 5 minutes; therefore, $\Delta t=1 / 12=0.0833$ hours. To calculate $\mathrm{Q}_{\mathrm{i}}$, the battery capacity $(10 \mathrm{KW})$ should be divided by its open circuit voltage $(400 \mathrm{~V})$; therefore, $\mathrm{Q}_{\mathrm{i}}=10,000 / 400=25 \mathrm{Ah}$. Detailed calculations of SOC using $Q_{i}$ are presented in Table A1.

In Coulomb counting technique, the charges flowing into and out of the battery are integrated to get an accurate estimate of the remaining capacity and calculation of SOC [36]. This technique uses a shunt to measure battery current, and a coulomb counting circuit which is effectively a very accurate current-integrating ADC (analog to digital) technique. Then, the measured battery voltage and current are sent to a microprocessor where the microprocessor contains battery chemistry specific information, such as cell impedance in its memory. To communicate with the rest of the system a standard protocol such as $\mathrm{I}^{2} \mathrm{C}$ communication can be used. Then, the SOC is calculated using Eqs. 4-9 (presented in section 3 and Table A1). Then, the SOC will be transmitted through Wi-Fi system to the central PEV charging coordination.

Practically, for real-time calculation of battery SOC at each time slot ( $\Delta t=5$ minutes), the following steps should be taken (see Table A1 for more details).

1- The battery ampere hour rate is calculated as $Q i=($ Battery Capacity $) / V_{o c}$.

2- Measuring open circuit voltages of the PEV batteries $\left(V_{o c}\right)$.

3- Measuring the battery current using a shunt.

4- Sent the measured battery voltage and current to the microprocessor using a standard protocol such as $\mathrm{I}^{2} \mathrm{C}$ communication.

5- Using Equation 7-9 to calculate SOC.

6- Transmitting the SOC to the central PEV charging coordination center through Wi-Fi system.

Note that if the battery is connected to a charger with $\mathrm{CR}=0.3$, then the required time (without considering losses) to fully charge the battery is $1 / 0.3=3.333$ hours. If we consider the impacts of the losses, then the battery will only be charged to $86 \%$ of its rated capacity. Therefore, more time will be required to fully charge the battery if the losses are included. 


\section{APPENDIX B: DETAILS OF THE THREE SIMULATED CASES STUDIES}

The selected input parameters for the simulation cases with $63 \%$ PEV penetration are provided in Table B1. This table presents the selected battery and charger types for each bus with PEV as well as the selected random values for initial SOCs, requested SOCs, plug-in times and plug-out times. The selected charger and battery types are:

- $\quad$ Charger Type: $\mathrm{A}=3.3 \mathrm{~kW}, \mathrm{~B}=7.2 \mathrm{~kW}$ and $\mathrm{C}=6.6 \mathrm{~kW}$

- $\quad$ Battery type: $\mathrm{D}=6 \mathrm{kWh}, \mathrm{E}=19.2 \mathrm{kWh}$ and $\mathrm{F}=16 \mathrm{kWh}$ 


\section{REFERENCES}

[1] W. Su, H. Rahimi-Eichi, W. Zeng, M.Y. Chow, "A survey on the electrification of transportation in a smart grid environment”, IEEE Trans. on Power Systems, Vol.3, No.1, pp.1-10, 2012.

[2] K. Clement-Nyns, E. Haesen, J. Driesen, "The impact of vehicle-to-grid on the distribution grid", Electric Power Systems Research, Vol.81, No.1, pp.185-192, 2011.

[3] S. Deilami, A.S. Masoum, P.S. Moses, M.A.S. Masoum, "Real-time coordination of plug-in electric vehicle charging in smart grids to minimize power losses and improve voltage profile”, IEEE Trans. on Smart Grid, Vol.2, No.3, pp.456-467, 2011.

[4] M.F. Shaaban, M. Ismail, E.F. El-Saadany, W. Zhuang, "Real-time PEV charging/discharging coordination in smart distribution systems,” IEEE Trans. on Smart Grid, Vol.5, No.4, pp.1797-1807, 2015.

[5] E. Gerding et al., “Online mechanism design for electric vehicle charging,” International Conference of Autonomous Multi agent System, pp.811-818, 2011.

[6] Y. He, B. Venkatesh, and L. Guan, “Optimal scheduling for charging and discharging of electric vehicles,” IEEE Trans. Smart Grid, Vol.3, No.3, pp. 1095-110, 2012.

[7] C.K. Wen, J.C. Chen, J.H. Teng, P. Ting, "Decentralized plug-in electric vehicle charging selection algorithm in power systems,” IEEE Trans. On Smart Grid, Vol.3, No.4, pp.1779-1789, 2012.

[8] S. Han, S. Han, K. Sezaki, "Development of an optimal vehicle to grid aggregator for frequency regulation”, IEEE Trans. on Smart Grid, Vol. 1, No. 1, 2010.

[9] E. Sortomme, M.A. El-Sharkawi, “Optimal charging strategies for unidirectional vehicle to grid”, IEEE Trans. on Smart Grid, Vol.2, No.1, pp.131-138, 2011.

[10] M. Alonso, H. Amaris, J.G. Germain, J. M. Galan, “optimal charging scheduling of electric vehicles in smart grids by heuristic algorithms", Journal of Energies, Vol.7, No.4, 2014.

[11] D.T. Nguyen, L.B. Le, "Joint optimization of electric vehicle and home scheduling considering user comfort preference”, IEEE Trans. on Smart Grid, Vol.5, No.1, pp.188-199, 2014.

[12] X. Luo, K.W. Chan, "Real time scheduling of electric vehicles charging in low-voltage residential distribution systems to minimize power losses and improve voltage profile”, IET Proceedings on Generation, Transmission and Distribution, Vol.8, No.3, pp.516-529, 2013.

[13] I. Sharma, C. Canizares, B. Bhattacharya, "Smart charging of PEVs penetrating into residential distribution systems", IEEE Trans. on Smart Grid, Vol.5, No.3, pp.1196-1209, 2014.

[14] M.H. Amirioun, A. Kazemi, “A new model based on optimal scheduling of combined energy exchange for aggregation of electric vehicles in a residential complex”, IEEE Journal on Energies, Vol.69, pp.186-198, 2014.

[15] C.T. Li, C. Ahn, H. Peng, J. Sun, "Synergistic Control of Plug-In Vehicle Charging and Wind Power Scheduling", IEEE Trans. on Power Systems, Vol.28, No.2, pp.1113-1121, 2013. 
[16] L. Gan, U. Topcu, and S. H. Low, "Optimal decentralized protocol for electric vehicle charging," IEEE Trans. on Power Systems, Vol.28, No.2, pp.940-951, 2013.

[17] J. Dixon, I. Nakashima, E.F. Arcos, M. Ortuzar, "Electric vehicle using a combination of ultracapacitors and ZEBRA battery”, IEEE Trans. on Industrial Electronics, Vol.57, No.3, pp. -943-949, 2010.

[18] N. Hartmann, E.D. Ozdemir, "Impact of different utilization scenarios of electric vehicles on the German grid in 2030", Journal of Power Sources, Vol.196, No.4, pp. -2311-2318, 2011.

[19] Staunton RH, Ayers CW, Marlino LD, Chiasson JN, Burress TA, "Evaluation of 2004 Toyota Prius hybrid electric drive system”, US Department of Energy Report, 2006.

[20] K.M. Tsang, L. Sun, W.L. Chan, "Identification and modeling of Lithium Ion battery", Energy Conversion and Management, pp.2857-2862, 2010.

[21] Wenhua H. Zhu, Ying Zhu, B.J. Tatarchuk, “A simplified equivalent circuit model for simulation of Pb-Acid batteries at load for energy storage application”, Energy Conversion and Management, pp. 2794-2799, 2011.

[22] T-K. Lee, Z. Baraket, T. Gordon, Z. Filipi, "Stochastic modeling for studies of real-world PHEV usage: driving schedules and daily temporal distributions,” IEEE Trans. on Vehicular Technology, Vol.61, No.4, pp. 1493-1502, 2012.

[23] http://www.chargepoint.com/evs

[24] S. Hajforoosh, S.M.H. Nabavi, M.A.S. Masoum, “Coordinated aggregated-based particle swarm optimisation algorithm for congestion management in restructured power market by placement and sizing of unified power flow controller," IET Science Measurement \& Technology, Vol.6, No.4, pp.267-278, 2012.

[25] J.G. Vlachogiannis, K.Y. Lee, “A comparative study on particle swarm optimization for optimal steady-state performance of power systems”, IEEE Trans. on Power Systems, Vol.21, No.4, pp.1718-1728, 2006.

[26] A. S. Masoum, S. Deilami, A. Abu-Siada and M. A. S. Masoum, "Fuzzy approach for online coordination of plug-in electric vehicle charging in smart grid”, IEEE Trans. on Sustainable Energy, Vol.6, No.3, pp.1112-1121, 2015. [27] S. Hajforoosh, M. A.S. Masoum, S. M. Islam, "Real-time charging coordination of plug-in electric vehicles based on hybrid fuzzy discrete particle swarm optimization”, Electric Power Systems Research, Vol.128, pp.19-29, 2015.

[28] P. Papadopoulos, N. Jenkins, L. M. Cipcigan, I. Grau and E. Zabala, "Coordination of the charging of electric vehicles using a multi-agent system”, IEEE Trans. on Smart Grid, Vol.4, No.4, pp.1802-1809, 2013.

[29] A. Zakariazadeh, S. Jadid, P. Siano, "Multi-objective scheduling of electric vehicles in smart distribution system", Energy Conversion and Management, Vol.79, pp.43-53, 2014.

[30] J. Soares, M.A. Fotouhi Ghazvini, M. Silva, Z. Vale, "Multi-dimensional signalling method for population-based metaheuristics: solving the large-scale scheduling problem in smart grids", Swarm and Evolutionary Computation, In Press, 2016. 
[31]Y. Luo, T. Zhu, S. Wan, S. Zhang, K. Li, "Optimal charging scheduling for large-scale EV (Electric Vehicle) deployment based on the interaction of the smart-grid and intelligent-transport Systems", Energy ,Vol.97, pp.359-368, 2016.

[32] J. Jiang, C. Zhang, "Fundamentals and application of lithium-ion batteries in electric drive vehicles", John Wiley \& Sons, 2015.

[33] H. He, R. Xiong, J. Fan, "Evaluation of lithium-ion battery equivalent circuit models for state of charge estimation by an experimental approach", Energies, Vol.4, No.4, pp.582-598, 2011.

[34] J.G. Vlachogiannis, K.Y. Lee, “A comparative study on particle swarm optimization for optimal steady-state performance of power systems", IEEE Trans. on Power System, Vol.21, No.4, pp.1718-1728, 2006.

[35] T. Li, W. Tang, “An improved adaptive particle swarm optimization algorithm”, Information Engineering and Applications, Vol.154, pp.331-338, 2012.

[36] https://www.ecnmag.com/article/2012/11/fundamentals-battery-fuel-gauging.

[37] M.M. Mahmoud, "On the storage batteries used in solar electric power systems and development of an algorithm for determining their ampere-hour capacity, Electric Power Systems Research”, Vol. 71, pp. 85-89, 2004.

[38] P. Sabine, P. Marion, J. Andreas, "Methods for state-of-charge determination and their applications", Journal of Power Sources, Vol. 96, pp 113-120, 2001.

[39] P.E. Pascoe, A.H. Anbuky, "Estimation of VRLS battery capacity using the analysis of coup de fouet region", Telecommunication Energy Conference (INTELEC), 1999.

[40] C.h. Ehret, S. Piller, W. Schroer, A. Jossen, "State-of-charge determination for lead-acid batteries in PV-applications", European Photovoltaic Solar Energy Conference, pp. 2486-2489, 2000. 
Table I: Impact of PEV charging on the SG of Fig. 2(c).

Table II: Detailed simulation results for coordinated (CAPSO) PEV charging of Fig. 2(c) for worst, moderate and best feeders using FCC and VCC.

Table III: Detailed comparison of the proposed CAPSO based PEV coordination approach with the implemented strategies in references $26-28$.

Table A1: Calculation of SOC based on Eqs. 6-9.

Table B1: Selected input parameters for the three simulated cases studies 
TABLE I

\begin{tabular}{|c|c|c|c|c|}
\hline $\begin{array}{l}\text { PEV } \\
{[\%]}\end{array}$ & $\begin{array}{l}\Delta \mathbf{V}^{*} \\
{[\%]}\end{array}$ & $\begin{array}{l}\text { IMAX } \\
{[\%]^{* *}}\end{array}$ & $\begin{array}{c}\text { Customer } \\
\text { Satisfaction }\end{array}$ & $\begin{array}{l}\text { Computing } \\
\text { time*** (Sec) }\end{array}$ \\
\hline \multicolumn{5}{|c|}{ Nominal Case: With no PEV } \\
\hline 0 & 7.63 & 0 & NA & NA \\
\hline \multicolumn{5}{|c|}{ Case A: Uncoordinated PEV Charging; Fig. 3} \\
\hline 16 & 10.08 & 18.42 & NA & NA \\
\hline 32 & 12.60 & 19.58 & NA & NA \\
\hline 47 & 25.10 & 37.62 & NA & NA \\
\hline 63 & 31.00 & 45.27 & NA & NA \\
\hline \multicolumn{5}{|c|}{ Online PEV Coordination (DPSO) with FCC (Ref. [27]) } \\
\hline 16 & 9.32 & 0.82 & NA & 0.026 \\
\hline 32 & 9.38 & 0.93 & NA & 0.028 \\
\hline 47 & 9.90 & 0.99 & NA & 0.031 \\
\hline 63 & 9.90 & 2.72 & NA & 0.032 \\
\hline \multicolumn{5}{|c|}{ Case B: Online PEV Coordination (CAPSO) with FCC; Fig.4 } \\
\hline 16 & 9.42 & 1.39 & 98.37 & 0.027 \\
\hline 32 & 9.53 & 2.03 & 95.57 & 0.028 \\
\hline 47 & 9.91 & 2.09 & 90.54 & 0.032 \\
\hline 63 & 9.94 & 2.72 & 88.38 & 0.034 \\
\hline \multicolumn{5}{|c|}{ Case C: Online PEV Coordination (CAPSO) with VCC; Fig.5 } \\
\hline 16 & 9.06 & 0.00 & 99.09 & 0.028 \\
\hline 32 & 9.16 & 0.00 & 96.91 & 0.029 \\
\hline 47 & 9.58 & 0.00 & 94.47 & 0.034 \\
\hline 63 & 9.73 & 0.00 & 93.89 & 0.035 \\
\hline
\end{tabular}

*) Average voltage deviation over 24 hours.

**) Increase in transformer current compared with nominal case (no PEVs).

***) Intel Core i5-3570 $3.40 \mathrm{GHz}$ processor, 8 GB RAM, using MATLAB ver. 8 


\begin{tabular}{|c|c|c|c|c|c|c|c|c|c|c|c|c|c|c|}
\hline \multicolumn{2}{|l|}{ Node Number } & $\mathbf{b}$ & D & $\mathbf{f}$ & $\mathbf{g}$ & $\mathbf{h}$ & $\mathbf{j}$ & 1 & $\mathbf{m}$ & $\mathbf{o}$ & $\mathbf{q}$ & $\mathbf{r}$ & $\mathbf{s}$ & Ave. \\
\hline \multicolumn{15}{|c|}{ For the Worst Feeder (DT-14) } \\
\hline \multirow{2}{*}{\multicolumn{2}{|c|}{$\begin{array}{c}\text { Plug-in Time Slot } \\
\text { Initial SOC }[\%] \\
\end{array}$}} & 21 & 14 & 20 & 15 & 19 & 24 & 25 & 21 & 21 & 23 & 28 & 36 & 22 \\
\hline & & 9 & 12 & 5 & 8 & 2 & 19 & 11 & 9 & 19 & 5 & 22 & 20 & 11 \\
\hline \multicolumn{2}{|l|}{ Requested Plug-Out Time Slot } & 103 & 58 & 84 & 62 & 77 & 151 & 157 & 104 & 112 & 145 & 167 & 175 & 116 \\
\hline \multicolumn{2}{|l|}{ Request SOC [\%] } & 62 & 92 & 99 & 89 & 82 & 72 & 70 & 83 & 61 & 68 & 80 & 67 & 77 \\
\hline \multicolumn{2}{|l|}{ Actual SOC at TReq for VCC [\%] } & 62 & 22 & 36 & 42 & 19 & 72 & 70 & 83 & 61 & 68 & 80 & 67 & 57 \\
\hline \multicolumn{2}{|l|}{ Actual SOC at TReq for FCC [\%] } & 0 & 0 & 0 & 89 & 0 & 52 & 70 & 83 & 61 & 68 & 80 & 67 & 487 \\
\hline \multirow{2}{*}{ Consumer Satisfaction (Eq.3) [\%] } & VCC & 100 & 24 & 36 & 48 & 24 & 100 & 100 & 100 & 100 & 100 & 100 & 100 & 78 \\
\hline & FCC & 0 & 0 & 0 & 100 & 0 & 72 & 100 & 100 & 100 & 100 & 100 & 100 & 64 \\
\hline \multicolumn{15}{|c|}{ For the Moderate Feeder (DT-12) } \\
\hline \multicolumn{2}{|l|}{ Plug-in Time Slot } & 73 & 83 & 46 & 42 & 55 & 54 & 63 & 42 & 61 & 68 & 51 & 50 & 57 \\
\hline \multirow{2}{*}{\multicolumn{2}{|c|}{$\begin{array}{c}\text { Initial SOC [\%] } \\
\text { Requested Plug-Out Time Slot }\end{array}$}} & 26 & 7 & 12 & 23 & 18 & 28 & 4 & 28 & 7 & 17 & 27 & 20 & 18 \\
\hline & & 198 & 205 & 184 & 181 & 189 & 188 & 192 & 181 & 192 & 194 & 187 & 186 & 189 \\
\hline \multicolumn{2}{|l|}{ Request SOC [\%] } & 84 & 59 & 73 & 94 & 97 & 64 & 93 & 65 & 68 & 66 & 53 & 57 & 72 \\
\hline \multirow{2}{*}{\multicolumn{2}{|c|}{$\begin{array}{l}\text { Actual SOC at TReq for VCC [\%] } \\
\text { Actual SOC at TReq for FCC [\%] }\end{array}$}} & 84 & 59 & 73 & 94 & 97 & 64 & 93 & 65 & 68 & 66 & 53 & 57 & 72 \\
\hline & & 84 & 59 & 73 & 94 & 97 & 29 & 93 & 65 & 68 & 66 & 53 & 57 & 69 \\
\hline \multirow{2}{*}{ Consumer Satisfaction (Eq.3) [\%] } & $\mathrm{VCC}$ & 100 & 100 & 100 & 100 & 100 & 100 & 100 & 100 & 100 & 100 & 100 & 100 & 100 \\
\hline & FCC & 100 & 100 & 100 & 100 & 100 & 0 & 100 & 100 & 100 & 100 & 100 & 100 & 91 \\
\hline \multicolumn{15}{|c|}{ For the Best Feeder (DT-20) } \\
\hline \multicolumn{2}{|l|}{ Plug-in Time Slot } & 76 & 61 & 36 & 51 & 64 & 83 & 38 & 85 & 114 & 49 & 68 & 46 & 64 \\
\hline \multicolumn{2}{|l|}{ Initial SOC [\%] } & 9 & 24 & 7 & 3 & 28 & 26 & 16 & 12 & 8 & 21 & 21 & 28 & 16 \\
\hline \multicolumn{2}{|l|}{ Requested Plug-Out Time Slot } & 201 & 192 & 176 & 188 & 193 & 205 & 178 & 207 & 216 & 185 & 195 & 184 & 193 \\
\hline \multicolumn{2}{|l|}{ Request SOC $[\%]$} & 58 & 84 & 74 & 76 & 76 & 57 & 55 & 60 & 52 & 74 & 58 & 56 & 65 \\
\hline \multicolumn{2}{|l|}{ Actual SOC at TReq for VCC [\%] } & 58 & 84 & 74 & 76 & 76 & 57 & 55 & 60 & 52 & 74 & 58 & 56 & 65 \\
\hline \multicolumn{2}{|l|}{ Actual SOC at TReq for FCC [\%] } & 58 & 84 & 74 & 76 & 76 & 57 & 55 & 60 & 52 & 74 & 58 & 56 & 65 \\
\hline \multirow{2}{*}{ Consumer Satisfaction (Eq.3) [\%] } & VCC & 100 & 100 & 100 & 100 & 100 & 100 & 100 & 100 & 100 & 100 & 100 & 100 & 100 \\
\hline & FCC & 100 & 100 & 100 & 100 & 100 & 100 & 100 & 100 & 100 & 100 & 100 & 100 & 100 \\
\hline
\end{tabular}


TABLE III

\begin{tabular}{|c|c|c|c|c|c|}
\hline & & $\begin{array}{c}\text { Proposed } \\
\text { in }[26]\end{array}$ & $\begin{array}{l}\text { Proposed } \\
\text { in [27] }\end{array}$ & $\begin{array}{l}\text { Proposed } \\
\text { in }[28]\end{array}$ & $\begin{array}{c}\text { Proposed in This } \\
\text { Paper }\end{array}$ \\
\hline \multicolumn{2}{|l|}{ Method } & Fuzzy & DPSO/GA Fuzzy & Multi Agent Based & CAPSO \\
\hline \multicolumn{2}{|c|}{ Charge Type } & FCC & FCC & $\mathrm{FCC}$ & VCC, FCC \\
\hline \multicolumn{2}{|c|}{ Battery Type } & One Type & Variety of Battery Types & One Type & $\begin{array}{c}\text { Variety of Battery } \\
\text { Types }\end{array}$ \\
\hline \multicolumn{2}{|c|}{ Battery Modelling } & NA & NA & $\checkmark$ & $\checkmark$ \\
\hline \multicolumn{2}{|c|}{ Charger Efficiency Effect } & NA & NA & NA & $\checkmark$ \\
\hline \multirow{3}{*}{$\begin{array}{l}\text { Customer } \\
\text { Preference }\end{array}$} & $S O C_{\operatorname{Re} q}(i)$ & NA & NA & $\checkmark$ & $\checkmark$ \\
\hline & $\operatorname{Bid}\left(\Delta t_{k}, i\right)$ & NA & NA & NA & $\checkmark$ \\
\hline & $T_{R e q}(i)$ & NA & NA & NA & $\checkmark$ \\
\hline \multicolumn{2}{|c|}{$\begin{array}{l}\text { Customer Satisfaction } \\
\text { Analysis }\end{array}$} & NA & NA & NA & $\checkmark$ \\
\hline \multicolumn{2}{|c|}{ Driving Pattern } & NA & $\checkmark$ & NA & $\sqrt{ }$ \\
\hline
\end{tabular}




\begin{tabular}{|c|c|}
\hline \multicolumn{2}{|l|}{ Input Data to Calculate SOC } \\
\hline$V_{o c}$ for the battery bank $(\mathrm{V})$ & 400 \\
\hline$R_{i}$ for the battery bank (ohm) & $125 \times 0.002=0.25$ \\
\hline Charger efficiency at $C R^{\text {Best }}$ based on Fig 2.a & 0.93 \\
\hline$C R^{\text {Best }}$ which is a sample of results for $i^{\text {th }} \mathrm{PEV}$ achieved by CAPSO & 0.30 \\
\hline Nominal charger capacity $P^{\text {consumed }}(\mathrm{W})$ & 10000 \\
\hline$\Delta t$ & 0.083 \\
\hline$S O C_{\text {Initial }}(\%)$ & 0 \\
\hline Rated battery ampere hour $Q_{i}(\mathrm{Ah})$ & $10000 \div 400=25$ \\
\hline \multicolumn{2}{|l|}{ Calculations } \\
\hline$I^{\text {Rated }}$ (considering losses) using Eq. $8(\mathrm{~A})$ & 6.450 \\
\hline$I^{\text {Rated }}$ (not considering losses) using Eq. 5 (A) & 7.5 \\
\hline \multicolumn{2}{|c|}{ Increment of SOC for the Next 5 Minutes Using Eq.9 } \\
\hline Increment of SOC for the next 5 minutes (considering losses) (\%) & 2.150 \\
\hline Increment of SOC for the next 5 minutes (not considering losses) $(\%)$ & 2.5 \\
\hline \multicolumn{2}{|c|}{ SOC After the Nominal Charge Time of $1 / 0.3=3.333$ Hours with $C R=0.3$} \\
\hline SOC after 3.333 hours (considering losses) (\%) & 86.0 \\
\hline SOC after 3.333 hours (not considering losses) (\%) & 100 \\
\hline
\end{tabular}


TABLE B1

\begin{tabular}{|c|c|c|c|c|c|c|c|c|c|c|c|c|c|}
\hline $\begin{array}{c}\text { Bus } \\
\#\end{array}$ & $\begin{array}{c}\text { SOC } \\
\text { Initial }\end{array}$ & $\begin{array}{l}\text { SOC } \\
\text { Req }\end{array}$ & $\begin{array}{l}\text { Battery } \\
\text { Type }\end{array}$ & $\begin{array}{c}\text { Charger } \\
\text { Type }\end{array}$ & $\begin{array}{l}\text { Plug-in } \\
\text { Time } 63\end{array}$ & $\begin{array}{l}\text { Plug-out } \\
\text { Time }\end{array}$ & $\begin{array}{c}\text { Bus } \\
\#\end{array}$ & $\begin{array}{l}\text { SOC } \\
\text { Initial }\end{array}$ & $\begin{array}{l}\text { SOC } \\
\text { Req }\end{array}$ & $\begin{array}{c}\text { Battery } \\
\text { Type }\end{array}$ & $\begin{array}{c}\text { Charger } \\
\text { Type }\end{array}$ & $\begin{array}{c}\text { Plug-in } \\
\text { Time }\end{array}$ & $\begin{array}{c}\text { Plug-out } \\
\text { Time }\end{array}$ \\
\hline 2 & 18 & 89 & $\mathrm{E}$ & $\mathrm{B}$ & 22 & 135 & 222 & 26 & 84 & $\mathrm{~F}$ & $\mathrm{C}$ & 73 & 198 \\
\hline 4 & 14 & 90 & $\mathrm{~F}$ & $\mathrm{C}$ & 24 & 154 & 224 & 7 & 59 & D & A & 83 & 205 \\
\hline 6 & 25 & 53 & $\mathrm{~F}$ & $\mathrm{C}$ & 18 & 77 & 226 & 12 & 73 & $\mathrm{D}$ & $\mathrm{A}$ & 46 & 184 \\
\hline 7 & 2 & 82 & E & B & 22 & 144 & 227 & 23 & 94 & E & B & 42 & 181 \\
\hline 8 & 20 & 92 & E & B & 44 & 182 & 228 & 18 & 97 & $\mathrm{~F}$ & C & 55 & 189 \\
\hline 10 & 27 & 63 & $\mathrm{~F}$ & C & 15 & 60 & 230 & 28 & 64 & $\mathrm{~F}$ & C & 54 & 188 \\
\hline 12 & 4 & 56 & E & B & 92 & 211 & 232 & 4 & 93 & E & B & 63 & 192 \\
\hline 13 & 14 & 71 & $E$ & $\mathrm{~B}$ & 62 & 192 & 233 & 28 & 65 & $\mathrm{~F}$ & $\mathrm{C}$ & 42 & 181 \\
\hline 15 & 10 & 73 & $F$ & $\mathrm{C}$ & 6 & 52 & 235 & 7 & 68 & $\mathrm{D}$ & $\mathrm{A}$ & 61 & 192 \\
\hline 17 & 28 & 82 & $\mathrm{~F}$ & $\mathrm{C}$ & 24 & 149 & 237 & 17 & 66 & $\mathrm{E}$ & B & 68 & 194 \\
\hline 18 & 0 & 96 & $E$ & B & 45 & 183 & 238 & 27 & 53 & $\mathrm{~F}$ & $\mathrm{C}$ & 51 & 187 \\
\hline 19 & 11 & 72 & D & A & 13 & 53 & 239 & 20 & 57 & $\mathrm{D}$ & A & 50 & 186 \\
\hline 22 & 24 & 69 & $\mathrm{~F}$ & $\mathrm{C}$ & 38 & 176 & 242 & 10 & 52 & $\mathrm{~F}$ & $\mathrm{C}$ & 110 & 216 \\
\hline 24 & 24 & 83 & $\mathrm{~F}$ & $\mathrm{C}$ & 69 & 196 & 244 & 2 & 62 & $F$ & $\mathrm{C}$ & 68 & 194 \\
\hline 26 & 23 & 92 & $\mathrm{~F}$ & $\mathrm{C}$ & 44 & 182 & 246 & 2 & 89 & $F$ & $\mathrm{C}$ & 68 & 195 \\
\hline 27 & 23 & 51 & $F$ & $\mathrm{C}$ & 46 & 184 & 247 & 8 & 85 & $F$ & $\mathrm{C}$ & 42 & 181 \\
\hline 28 & 8 & 92 & $E$ & B & 27 & 166 & 248 & 13 & 96 & $E$ & B & 33 & 174 \\
\hline 30 & 29 & 97 & $\bar{E}$ & B & 36 & 176 & 250 & 16 & 65 & $\mathrm{E}$ & B & 75 & 200 \\
\hline 32 & 10 & 55 & $E$ & $\mathrm{~B}$ & 20 & 98 & 252 & 21 & 53 & $\mathrm{D}$ & A & 55 & 189 \\
\hline 33 & 28 & 55 & $\bar{E}$ & B & 54 & 189 & 253 & 10 & 59 & $E$ & B & 72 & 197 \\
\hline 35 & 23 & 52 & E & B & 38 & 177 & 255 & 8 & 67 & $F$ & $\mathrm{C}$ & 42 & 181 \\
\hline 37 & 11 & 53 & $\mathrm{~F}$ & $\mathrm{C}$ & 63 & 192 & 257 & 4 & 61 & $\mathrm{D}$ & $\mathrm{A}$ & 77 & 201 \\
\hline 38 & 22 & 88 & $\mathrm{~F}$ & $\mathrm{C}$ & 72 & 197 & 258 & 10 & 82 & $F$ & $\mathrm{C}$ & 23 & 144 \\
\hline 39 & 10 & 82 & $E$ & B & 69 & 196 & 259 & 24 & 81 & $E$ & B & 90 & 210 \\
\hline 42 & 21 & 97 & $E$ & B & 51 & 188 & 262 & 9 & 62 & $\mathrm{D}$ & $\mathrm{A}$ & 21 & 103 \\
\hline 44 & 28 & 67 & D & $\mathrm{A}$ & 72 & 197 & 264 & 12 & 92 & $F$ & $\mathrm{C}$ & 14 & 58 \\
\hline 46 & 1 & 78 & D & A & 64 & 193 & 266 & 5 & 99 & $\mathrm{E}$ & B & 20 & 84 \\
\hline 47 & 27 & 81 & $\mathrm{D}$ & A & 55 & 189 & 267 & 8 & 89 & $F$ & $\mathrm{C}$ & 15 & 62 \\
\hline 48 & 1 & 69 & $F$ & C & 58 & 191 & 268 & 2 & 82 & $\mathrm{E}$ & B & 19 & 77 \\
\hline 50 & 4 & 85 & $E$ & B & 68 & 195 & 270 & 19 & 72 & $\mathrm{E}$ & B & 24 & 151 \\
\hline 52 & 8 & 54 & $\mathrm{D}$ & $\mathrm{A}$ & 50 & 186 & 272 & 11 & 70 & $\mathrm{E}$ & B & 25 & 157 \\
\hline 53 & 19 & 74 & $\mathrm{E}$ & $\mathrm{B}$ & 38 & 178 & 273 & 9 & 83 & D & $\mathrm{A}$ & 21 & 104 \\
\hline 55 & 2 & 88 & $\mathrm{~F}$ & $\mathrm{C}$ & 56 & 190 & 275 & 19 & 61 & D & A & 21 & 112 \\
\hline 57 & 15 & 71 & $\mathrm{~F}$ & $\mathrm{C}$ & 62 & 192 & 277 & 5 & 68 & $F$ & $\mathrm{C}$ & 23 & 145 \\
\hline 58 & 21 & 71 & $\mathrm{D}$ & A & 69 & 196 & 278 & 22 & 80 & $\mathrm{~F}$ & $\mathrm{C}$ & 28 & 167 \\
\hline 59 & 2 & 57 & $\mathrm{D}$ & A & 58 & 191 & 279 & 20 & 67 & $E$ & $B$ & 36 & 175 \\
\hline 62 & 24 & 70 & E & B & 50 & 187 & 282 & 24 & 96 & $\mathrm{~F}$ & $\mathrm{C}$ & 29 & 169 \\
\hline 64 & 22 & 83 & $E$ & B & 71 & 197 & 284 & 18 & 57 & $\mathrm{~F}$ & $\mathrm{C}$ & 20 & 91 \\
\hline 66 & 23 & 62 & $\mathrm{D}$ & $\mathrm{A}$ & 57 & 190 & 286 & 20 & 63 & $E$ & B & 29 & 170 \\
\hline 67 & 3 & 76 & $F$ & $\mathrm{C}$ & 75 & 200 & 287 & 19 & 87 & $\mathrm{E}$ & B & 21 & 118 \\
\hline 68 & 29 & 99 & $\mathrm{~F}$ & $\mathrm{C}$ & 57 & 190 & 288 & 21 & 94 & $\mathrm{~F}$ & $\mathrm{C}$ & 5 & 48 \\
\hline 70 & 11 & 90 & $E$ & B & 59 & 191 & 290 & 1 & 72 & $E$ & $\mathrm{~B}$ & 0 & 26 \\
\hline 72 & 27 & 56 & $\mathrm{~F}$ & $\mathrm{C}$ & 57 & 191 & 292 & 22 & 93 & $\mathrm{~F}$ & $\mathrm{C}$ & 6 & 53 \\
\hline 73 & 1 & 75 & $\mathrm{D}$ & A & 41 & 180 & 293 & 10 & 94 & $\mathrm{~F}$ & $\mathrm{C}$ & 21 & 122 \\
\hline 75 & 11 & 62 & $\mathrm{~F}$ & $\mathrm{C}$ & 40 & 179 & 295 & 24 & 55 & $\mathrm{D}$ & $\mathrm{A}$ & 17 & 71 \\
\hline 77 & 28 & 76 & D & A & 40 & 180 & 297 & 16 & 86 & $\mathrm{D}$ & A & 16 & 62 \\
\hline 78 & 23 & 63 & D & A & 95 & 212 & 298 & 6 & 89 & $\mathrm{D}$ & A & 23 & 146 \\
\hline 79 & 6 & 64 & $E$ & B & 55 & 190 & 299 & 11 & 77 & D & $\mathrm{A}$ & 16 & 66 \\
\hline 82 & 16 & 58 & $\mathrm{D}$ & $\mathrm{A}$ & 78 & 201 & 302 & 22 & 77 & D & A & 1 & 71 \\
\hline 84 & 28 & 54 & $E$ & B & 66 & 194 & 304 & 11 & 53 & $\mathrm{D}$ & A & 22 & 171 \\
\hline 86 & 5 & 80 & $\mathrm{E}$ & B & 96 & 212 & 306 & 7 & 86 & $\mathrm{D}$ & $\mathrm{A}$ & 31 & $\frac{171}{173}$ \\
\hline 87 & 22 & 83 & $\mathrm{E}$ & B & 78 & 202 & 307 & 18 & 74 & $\mathrm{E}$ & $\mathrm{B}$ & 47 & 184 \\
\hline 88 & 7 & 89 & $\mathrm{E}$ & B & 34 & 175 & 308 & 1 & 51 & $\mathrm{D}$ & $\mathrm{A}$ & 26 & $\frac{107}{163}$ \\
\hline 90 & 29 & 55 & $\mathrm{~F}$ & $\mathrm{C}$ & 52 & 188 & 310 & 7 & 97 & $\mathrm{~F}$ & C & 24 & $\frac{105}{154}$ \\
\hline 90 & 23 & $\frac{53}{72}$ & $F$ & $\mathrm{C}$ & $\frac{52}{77}$ & $\frac{100}{201}$ & $\frac{310}{312}$ & $\frac{1}{1}$ & 88 & $F$ & $\mathrm{C}$ & $\frac{24}{17}$ & $\frac{154}{72}$ \\
\hline 93 & 9 & 92 & $\mathrm{~F}$ & $\mathrm{C}$ & 65 & 193 & 313 & 6 & 65 & D & A & 21 & 125 \\
\hline 95 & 27 & 58 & $\mathrm{~F}$ & $\mathrm{C}$ & 104 & 215 & 315 & 5 & 100 & F & $\mathrm{C}$ & 22 & 143 \\
\hline 97 & 22 & 91 & $E$ & B & 58 & 191 & 317 & 23 & 89 & F & $\mathrm{C}$ & 5 & 50 \\
\hline 98 & 15 & 68 & $\mathrm{E}$ & B & 28 & 168 & 318 & 6 & 89 & E & B & 20 & 91 \\
\hline 99 & 0 & 53 & $\mathrm{D}$ & A & 68 & 195 & 319 & 4 & 60 & $\mathrm{~F}$ & $\mathrm{C}$ & 30 & 172 \\
\hline 102 & 3 & 56 & $\mathrm{D}$ & $\mathrm{A}$ & 41 & 180 & 322 & 11 & 81 & $\mathrm{~F}$ & $\mathrm{C}$ & 17 & 76 \\
\hline 104 & 14 & 66 & $\mathrm{E}$ & $\mathrm{B}$ & 60 & 191 & 324 & 4 & 83 & $\mathrm{E}$ & B & 28 & 168 \\
\hline 106 & 15 & 98 & D & A & 81 & 204 & 326 & 27 & 87 & $\mathrm{~F}$ & $\mathrm{C}$ & 33 & 175 \\
\hline 107 & 10 & 80 & $\mathrm{D}$ & $\mathrm{A}$ & 65 & 193 & 327 & 20 & 60 & $\mathrm{~F}$ & $\mathrm{C}$ & 34 & 175 \\
\hline 108 & 16 & 65 & D & $\mathrm{A}$ & 65 & 193 & 328 & 19 & 97 & E & B & 31 & 173 \\
\hline 110 & 24 & 8 & $\mathrm{~F}$ & C & 55 & 189 & 330 & 13 & 87 & $\mathrm{~F}$ & $\mathrm{~B}$ & 0 & 35 \\
\hline 112 & 16 & 78 & $E$ & B & 56 & 190 & 332 & 20 & 90 & $\mathrm{D}$ & $\mathrm{A}$ & 17 & 77 \\
\hline 113 & 29 & 75 & $\mathrm{E}$ & B & 57 & 190 & 333 & 7 & 55 & $\mathrm{D}$ & $\mathrm{A}$ & 32 & 173 \\
\hline 115 & 25 & 51 & $\mathrm{~F}$ & $\mathrm{C}$ & 3 & 46 & 335 & 24 & 74 & D & A & 9 & 53 \\
\hline 117 & 15 & 53 & $\bar{E}$ & $B$ & 67 & 194 & 337 & 1 & 81 & $\overline{\mathrm{F}}$ & $B$ & 60 & 19 \\
\hline 118 & 25 & 80 & $F$ & $\mathrm{C}$ & 79 & 202 & 338 & 9 & 100 & $\bar{D}$ & $\mathrm{~A}$ & 62 & 192 \\
\hline 119 & 11 & 72 & $\bar{E}$ & $\mathrm{~B}$ & 33 & 174 & 339 & 9 & 9 & $\bar{D}$ & $\mathrm{~A}$ & 51 & 187 \\
\hline 122 & 14 & 81 & $\mathrm{E}$ & B & 29 & 168 & 342 & 28 & 61 & 1 & $\mathrm{C}$ & 32 & 17 \\
\hline 124 & 3 & $\frac{11}{54}$ & $E$ & B & 71 & 197 & 344 & 21 & 94 & $\mathrm{~F}$ & $\mathrm{C}$ & 47 & 185 \\
\hline 126 & 6 & 71 & $\mathrm{~F}$ & $\bar{C}$ & 29 & 169 & 346 & 29 & 99 & $\bar{F}$ & $\mathrm{C}$ & 49 & 185 \\
\hline 127 & 15 & 67 & $\frac{1}{D}$ & A & 25 & $\frac{107}{155}$ & 347 & 5 & 81 & D & $\mathrm{A}$ & 66 & 193 \\
\hline 128 & 2 & 89 & $\bar{F}$ & $\overline{\mathrm{C}}$ & 75 & 199 & 348 & 16 & 59 & $\overline{1}$ & $\mathrm{C}$ & 60 & 19 \\
\hline 130 & 23 & 87 & $\bar{E}$ & $\bar{B}$ & 46 & 183 & 350 & 19 & 57 & $\overline{1}$ & 8 & 40 & 177 \\
\hline 132 & 14 & 60 & $\mathrm{E}$ & B & 84 & 205 & 352 & 9 & 80 & $\overline{1}$ & $\mathrm{~B}$ & 79 & 203 \\
\hline 133 & 3 & 63 & $\bar{F}$ & $\overline{\mathrm{C}}$ & 33 & 174 & 353 & 11 & 60 & $\overline{\mathrm{i}}$ & 8 & 46 & 184 \\
\hline 135 & 15 & 95 & $\mathrm{E}$ & B & 47 & 184 & 355 & 5 & 97 & $\overline{1}$ & $E$ & 31 & 173 \\
\hline 137 & 21 & 57 & $\bar{D}$ & A & 64 & 193 & 357 & 3 & 97 & $\mathrm{I}$ & & 38 & 177 \\
\hline 138 & 5 & 83 & $\mathrm{~F}$ & $\mathrm{C}$ & 70 & 196 & 358 & 23 & 91 & & & 64 & \\
\hline 139 & 9 & 89 & $\mathrm{E}$ & B & 68 & $\frac{190}{194}$ & 350 & $\frac{23}{12}$ & 69 & & & $\frac{04}{51}$ & $\frac{195}{187}$ \\
\hline
\end{tabular}




\begin{tabular}{|c|c|c|c|c|c|c|c|c|c|c|c|c|c|}
\hline 142 & 15 & 68 & D & A & 63 & 192 & 362 & 21 & 67 & $\mathrm{~F}$ & C & 65 & 193 \\
\hline 144 & 8 & 55 & $\mathrm{~F}$ & $\mathrm{C}$ & 54 & 188 & 364 & 19 & 54 & $\mathrm{~F}$ & $\mathrm{C}$ & 48 & 185 \\
\hline 146 & 16 & 59 & $\mathrm{~F}$ & $\mathrm{C}$ & 47 & 184 & 366 & 13 & 73 & D & A & 97 & 213 \\
\hline 147 & 16 & 80 & $\mathrm{E}$ & B & 69 & 195 & 367 & 27 & 71 & $E$ & B & 14 & 60 \\
\hline 148 & 23 & 99 & D & A & 51 & 187 & 368 & 1 & 51 & E & B & 39 & 179 \\
\hline 150 & 19 & 80 & $E$ & B & 67 & 194 & 370 & 8 & 72 & D & A & 45 & 183 \\
\hline 152 & 15 & 79 & $E$ & B & 81 & 204 & 372 & 23 & 62 & $\mathrm{E}$ & B & 49 & 185 \\
\hline 153 & 15 & 74 & $\mathrm{~F}$ & $\mathrm{C}$ & 14 & 55 & 373 & 0 & 73 & D & A & 76 & 200 \\
\hline 155 & 23 & 55 & $E$ & B & 95 & 211 & 375 & 17 & 80 & D & A & 51 & 188 \\
\hline 157 & 6 & 53 & $\mathrm{~F}$ & $\mathrm{C}$ & 46 & 184 & 377 & 19 & 74 & $F$ & $\mathrm{C}$ & 45 & 183 \\
\hline 158 & 14 & 88 & $\mathrm{~F}$ & $\mathrm{C}$ & 85 & 206 & 378 & 18 & 85 & $\mathrm{~F}$ & $\mathrm{C}$ & 48 & 185 \\
\hline 159 & 19 & 92 & D & $\mathrm{A}$ & 90 & 208 & 379 & 23 & 90 & $\mathrm{~F}$ & $\mathrm{C}$ & 62 & 192 \\
\hline 162 & 14 & 67 & $\mathrm{D}$ & $\mathrm{A}$ & 30 & 171 & 382 & 9 & 58 & D & $\mathrm{A}$ & 76 & 201 \\
\hline 164 & 8 & 81 & $E$ & B & 63 & 192 & 384 & 24 & 84 & $\mathrm{E}$ & B & 61 & 192 \\
\hline 166 & 8 & 63 & $\mathrm{E}$ & B & 128 & 217 & 386 & 7 & 74 & D & A & 36 & 176 \\
\hline 167 & 23 & 77 & $\mathrm{D}$ & A & 55 & 189 & 387 & 3 & 76 & $E$ & B & 51 & 188 \\
\hline 168 & 13 & 66 & $\mathrm{~F}$ & $\mathrm{C}$ & 69 & 195 & 388 & 28 & 76 & $E$ & B & 64 & 193 \\
\hline 170 & 25 & 93 & D & A & 66 & 193 & 390 & 26 & 57 & D & A & 83 & 205 \\
\hline 172 & 1 & 72 & $E$ & B & 84 & 206 & 392 & 16 & 55 & D & A & 38 & 178 \\
\hline 173 & 10 & 61 & $E$ & B & 81 & 203 & 393 & 12 & 60 & $\mathrm{~F}$ & $\mathrm{C}$ & 85 & 207 \\
\hline 175 & 19 & 81 & $\mathrm{D}$ & $\mathrm{A}$ & 40 & 179 & 395 & 8 & 52 & $F$ & $\mathrm{C}$ & 114 & 216 \\
\hline 177 & 29 & 65 & $\mathrm{~F}$ & $\mathrm{C}$ & 50 & 186 & 397 & 21 & 74 & D & $\mathrm{A}$ & 49 & 185 \\
\hline 178 & 26 & 77 & $E$ & B & 66 & 193 & 398 & 21 & 58 & D & $\mathrm{A}$ & 68 & 195 \\
\hline 179 & 25 & 100 & $\mathrm{~F}$ & $\mathrm{C}$ & 58 & 191 & 399 & 28 & 56 & $\mathrm{D}$ & $\mathrm{A}$ & 46 & 184 \\
\hline 182 & 26 & 97 & $E$ & B & 33 & 174 & 402 & 28 & 57 & $\mathrm{~F}$ & $\mathrm{C}$ & 25 & 159 \\
\hline 184 & 16 & 57 & $E$ & B & 56 & 190 & 404 & 17 & 81 & $\mathrm{~F}$ & $\mathrm{C}$ & 88 & 207 \\
\hline 186 & 15 & 72 & $\mathrm{~F}$ & $\mathrm{C}$ & 16 & 62 & 406 & 5 & 67 & $E$ & B & 73 & 198 \\
\hline 187 & 29 & 53 & D & A & 45 & 183 & 407 & 15 & 89 & D & A & 49 & 186 \\
\hline 188 & 14 & 81 & D & A & 28 & 167 & 408 & 22 & 62 & D & A & 61 & 192 \\
\hline 190 & 27 & 64 & $E$ & B & 34 & 175 & 410 & 1 & 87 & $\mathrm{~F}$ & $\mathrm{C}$ & 54 & 189 \\
\hline 192 & 21 & 83 & $\mathrm{~F}$ & $\mathrm{C}$ & 53 & 188 & 412 & 6 & 56 & $\mathrm{D}$ & A & 30 & 172 \\
\hline 193 & 25 & 72 & $\mathrm{~F}$ & $\mathrm{C}$ & 24 & 149 & 413 & 7 & 96 & $\mathrm{D}$ & $\mathrm{A}$ & 1 & 39 \\
\hline 195 & 11 & 64 & $E$ & B & 27 & 165 & 415 & 13 & 64 & $\mathrm{~F}$ & $\mathrm{C}$ & 58 & 191 \\
\hline 197 & 8 & 82 & D & $\mathrm{A}$ & 17 & 69 & 417 & 20 & 75 & $E$ & B & 50 & 186 \\
\hline 198 & 11 & 71 & $\mathrm{D}$ & $\mathrm{A}$ & 2 & 44 & 418 & 14 & 93 & $\mathrm{~F}$ & $\mathrm{C}$ & 47 & 185 \\
\hline 199 & 8 & 58 & $\mathrm{D}$ & A & 44 & 182 & 419 & 23 & 92 & $F$ & $\mathrm{C}$ & 42 & 182 \\
\hline 202 & 10 & 98 & $E$ & B & 70 & 196 & 422 & 14 & 52 & $E$ & B & 23 & 148 \\
\hline 204 & 7 & 57 & $\mathrm{D}$ & $\mathrm{A}$ & 43 & 182 & 424 & 10 & 79 & $\mathrm{~F}$ & $\mathrm{C}$ & 49 & 186 \\
\hline 206 & 6 & 70 & D & A & 42 & 180 & 426 & 24 & 85 & $E$ & B & 62 & 192 \\
\hline 207 & 0 & 74 & D & $\mathrm{A}$ & 26 & 161 & 427 & 25 & 92 & $\mathrm{E}$ & B & 38 & 178 \\
\hline 208 & 21 & 58 & $\mathrm{~F}$ & $\mathrm{C}$ & 79 & 202 & 428 & 11 & 99 & E & B & 68 & 195 \\
\hline 210 & 26 & 62 & $\mathrm{E}$ & B & 42 & 180 & 430 & 22 & 69 & D & A & 54 & 189 \\
\hline 212 & 15 & 99 & $\mathrm{~F}$ & C & 73 & 198 & 432 & 17 & 83 & $\mathrm{E}$ & B & 57 & 190 \\
\hline 213 & 12 & 77 & $\mathrm{~F}$ & C & 54 & 188 & 433 & 10 & 73 & D & A & 30 & 172 \\
\hline 215 & 14 & 73 & $E$ & B & 42 & 181 & 435 & 25 & 56 & $\mathrm{D}$ & $\mathrm{A}$ & 44 & 182 \\
\hline 217 & 25 & 58 & $\mathrm{D}$ & A & 69 & 196 & 437 & 4 & 79 & $E$ & B & 67 & 194 \\
\hline 218 & 22 & 63 & $\mathrm{~F}$ & $\mathrm{C}$ & 67 & 194 & 438 & 13 & 81 & D & A & 43 & 182 \\
\hline 219 & 21 & 64 & $E$ & B & 45 & 183 & 439 & 18 & 69 & $\mathrm{~F}$ & $\mathrm{C}$ & 62 & 192 \\
\hline
\end{tabular}


Fig. 1. Modeling of PEV battery [17]; (a) typical charger efficiency (CR corresponds to charging efficiencies), (b) equivalent circuit [21].

Fig. 2. System characteristics; (a) daily residential load curve (DLC) and short term market energy price (MEP) [3], (b) spectrums of the random plug-in times and the requested plug-out times of the simulated PEVs, (c) the 449 node SG consisting of IEEE 31-node $23 \mathrm{kV}$ system and 22 low voltage 19-node 415V residential feeders populated with PEVs [3], (d) detailed diagram of one residential feeder in Fig. 2(c) with 16\%, 32\%, 47\% and 63\% PEV penetrations.

Fig. 3. Simulation results for Case A with 16, 32, 47 and 63 percent of PEV penetrations; (a) loss power, (b) system power consumption, (c) weak bus voltage.

Fig. 4. Simulation results for Case B with 16, 32, 47 and 63 percent of PEV penetrations; (a) loss power, (b) system power consumption, (c) weak bus voltage.

Fig. 5. Simulation results for Case C with 16, 32, 47 and 63 percent of PEV penetrations; (a) loss power, (b) system power consumption, (c) weak bus voltage.

Fig.6. (a) Sample battery SOCs of feeders in Fig.2(c) for best feeder (DT-20) using FCC,

Fig.6. (b) Sample battery SOCs of feeders in Fig.2(c) for best feeder (DT-20) using VCC,

Fig.6. (c) Sample battery SOCs of feeders in Fig.2(c) for worst feeder (DT-14) using FCC,

Fig.6. (d) Sample battery SOCs of feeders in Fig.2(c) for worst feeder (DT-14) using VCC,

Fig.6. (e) Customer satisfaction of few feeders in Fig.2(c) using FCC and VCC for best feeder (DT-20),

Fig.6. (f) Customer satisfaction of few feeders in Fig.2(c) using FCC and VCC for worst feeder (DT-14),

Fig.6. (g) Customer satisfaction profiles for all feeders (DT-1 to DT-22) in Fig.2(c) using FCC,

Fig.6. (h) Customer satisfaction profiles for all feeders (DT-1 to DT-22) in Fig.2(c) using VCC. 
Figure 1

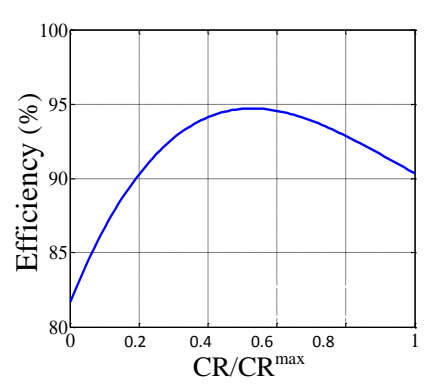

(a)

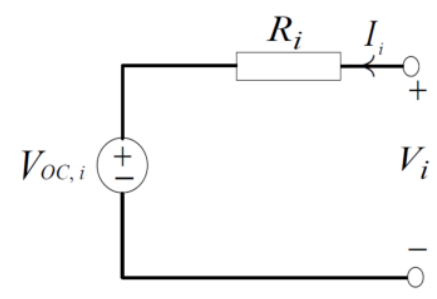

(b) 
Figure 2

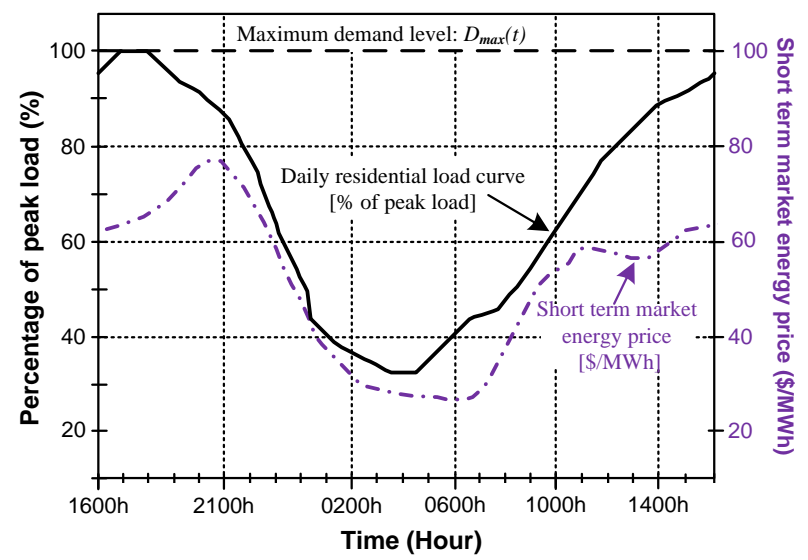

(a)

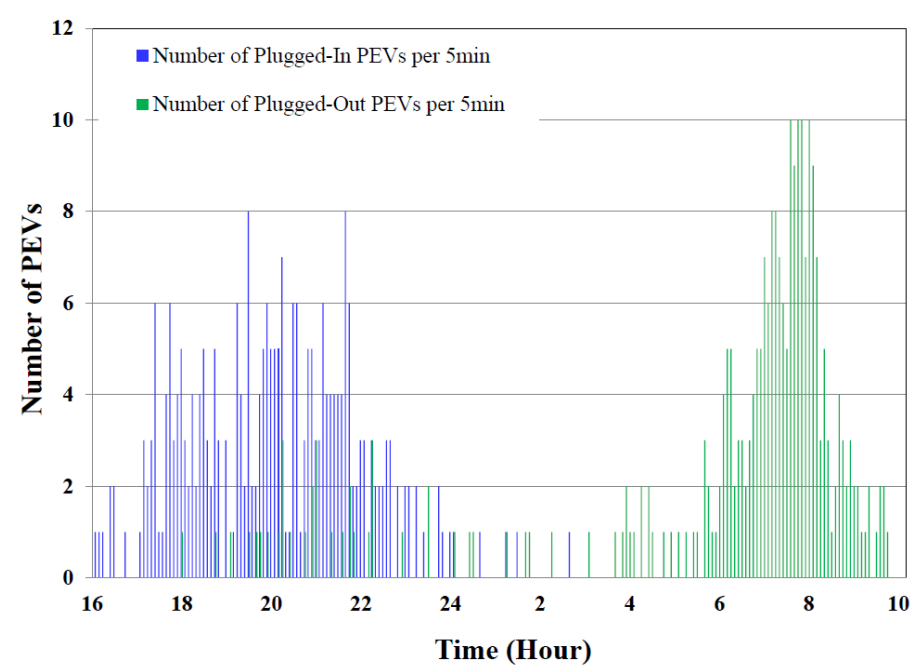

(b)

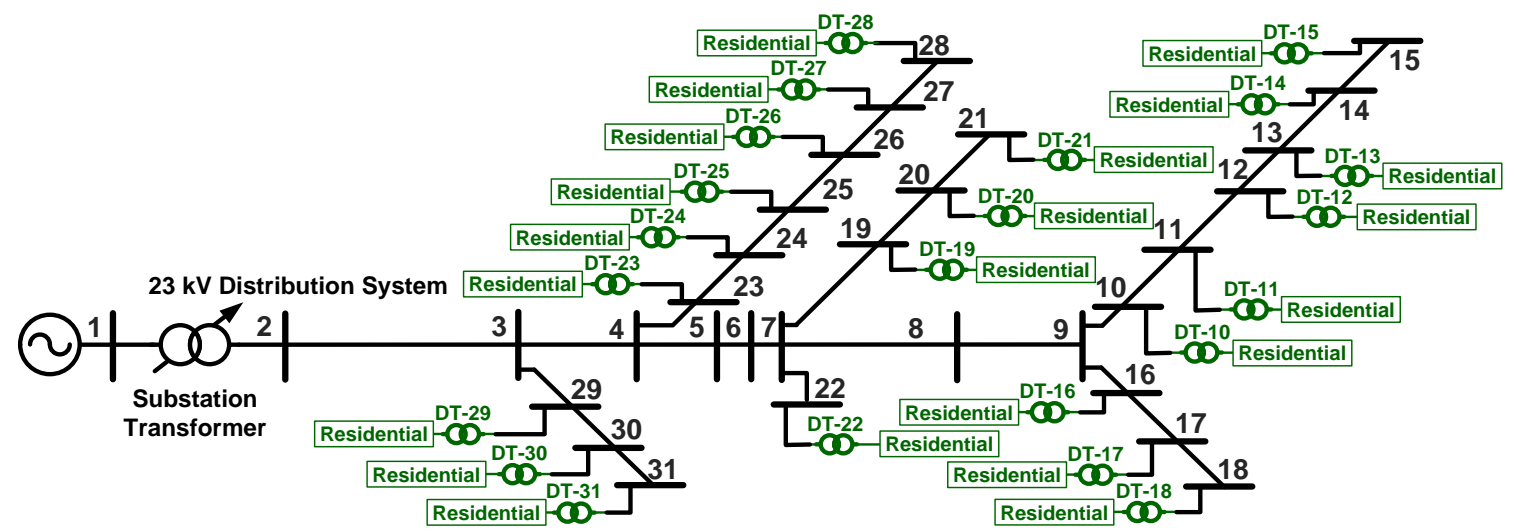

(c)

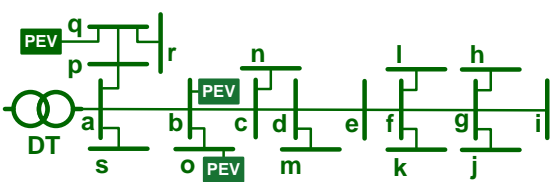

One residential feeder with $16 \%$ PEV penetration

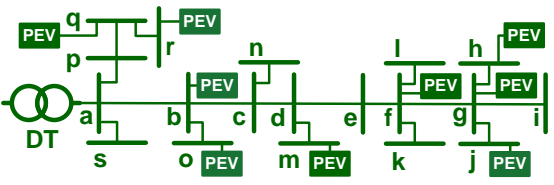

One residential feeder with $47 \%$ PEV penetration

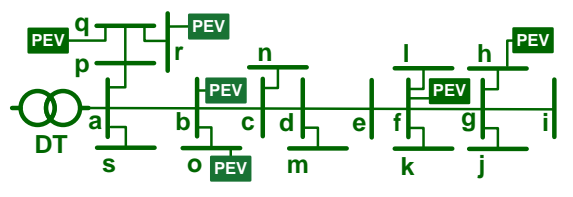

One residential feeder with $32 \% \mathrm{PEV}$ penetration

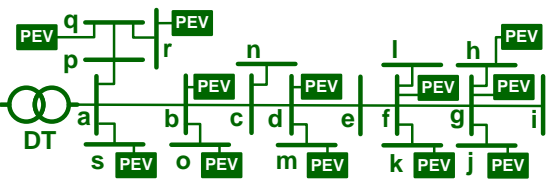

One residential feeder with $63 \% \mathrm{PEV}$ penetration

(d) 
Figure 3

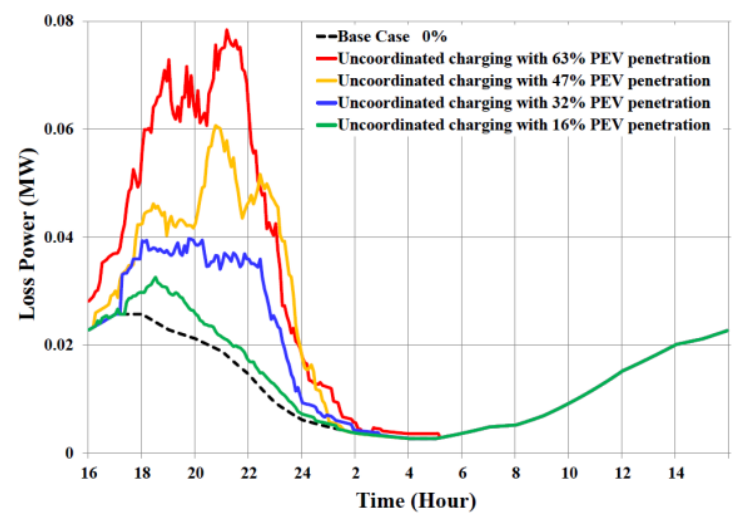

(a)

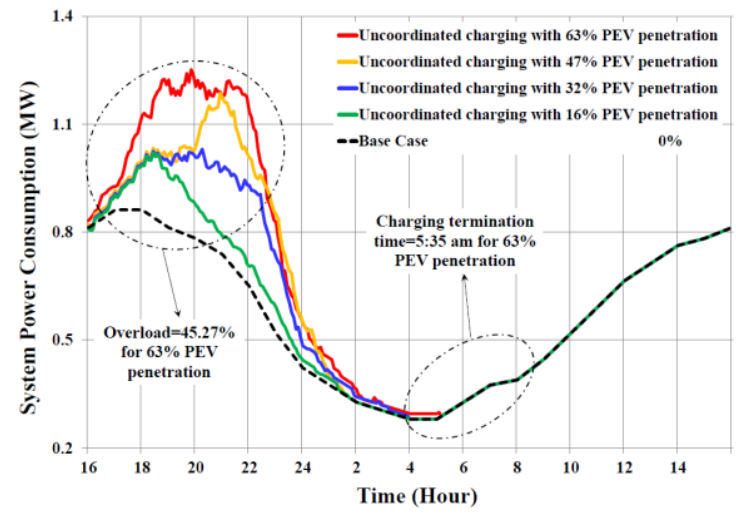

(b)

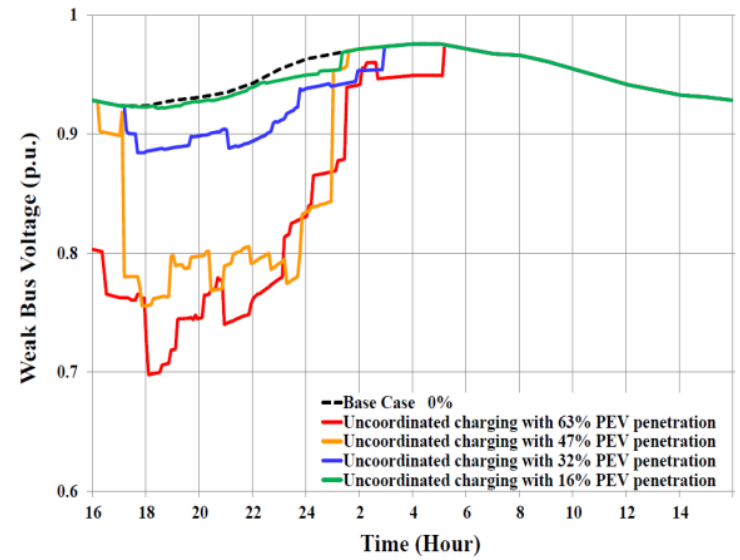

(c) 
Figure 4

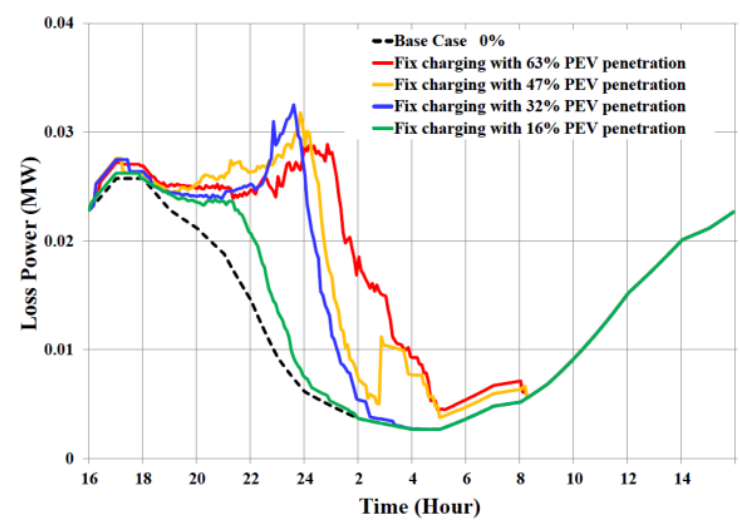

(a)

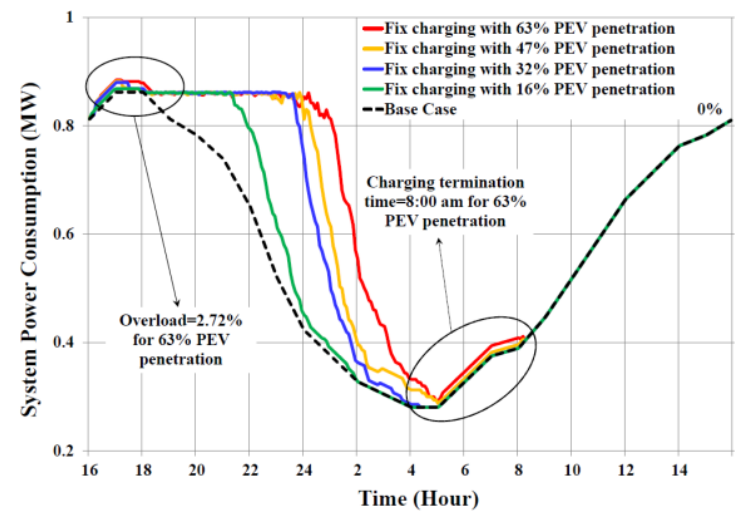

(b)

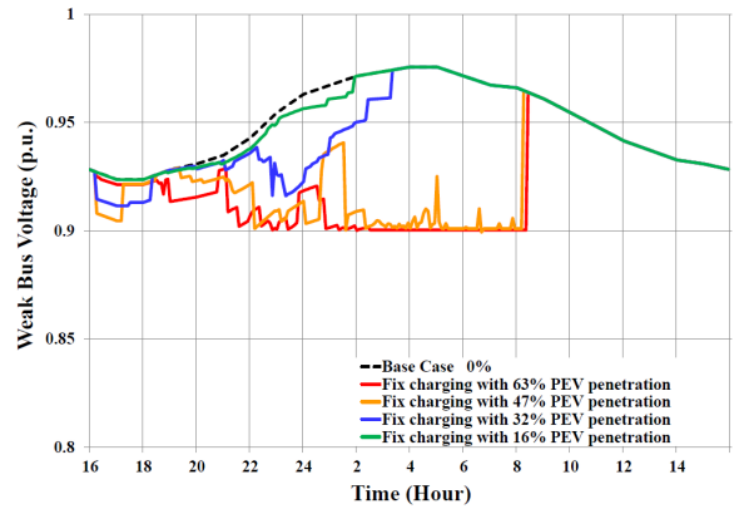

(c) 
Figure 5

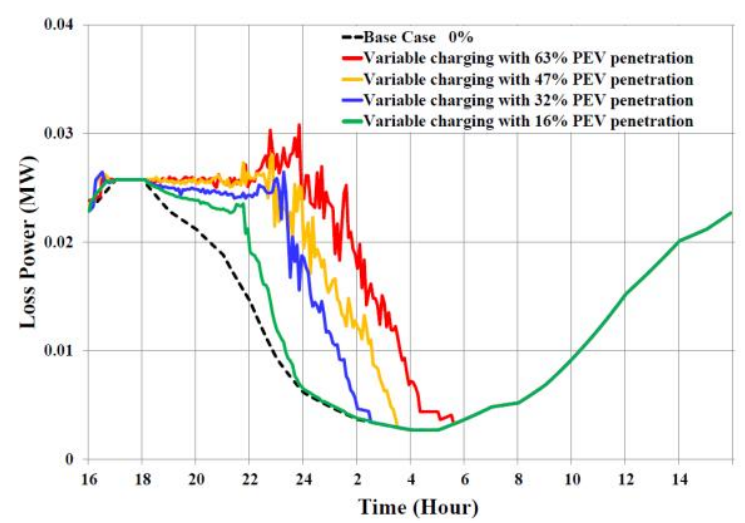

(a)

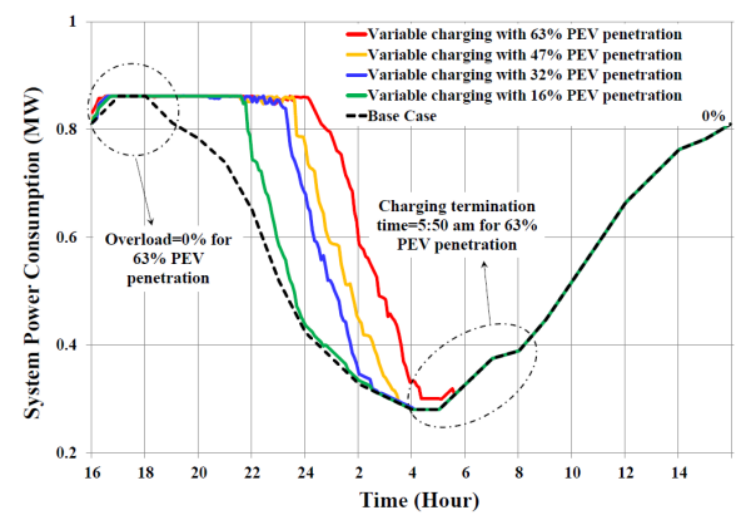

(b)

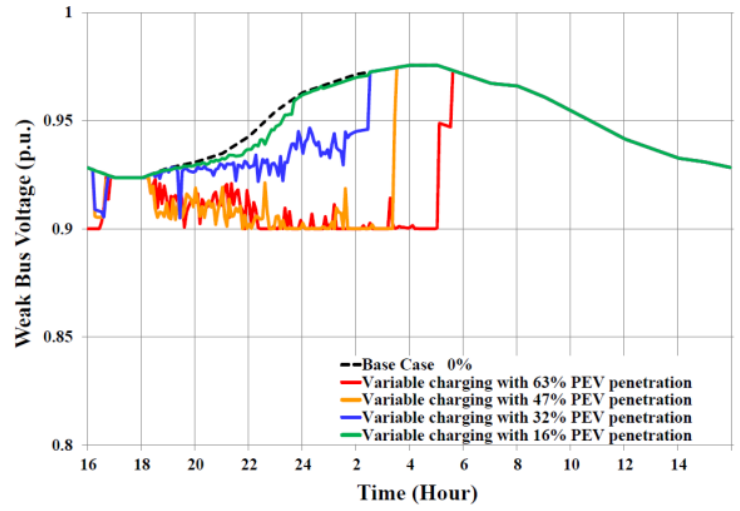

(c) 
Figure 6

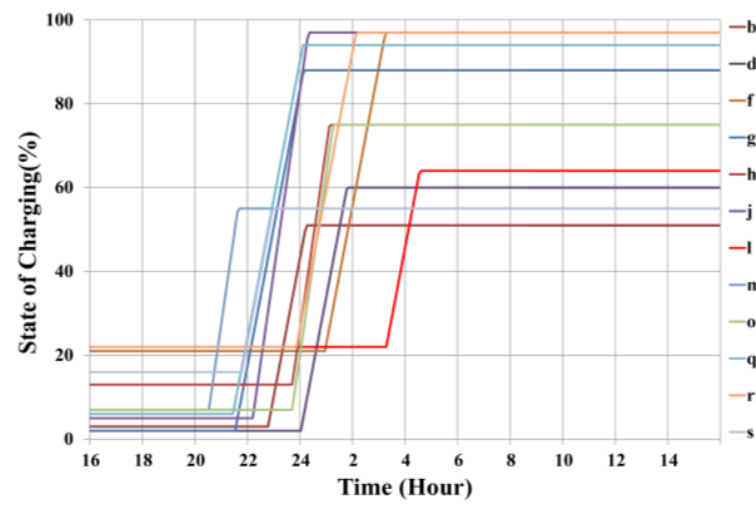

(a)

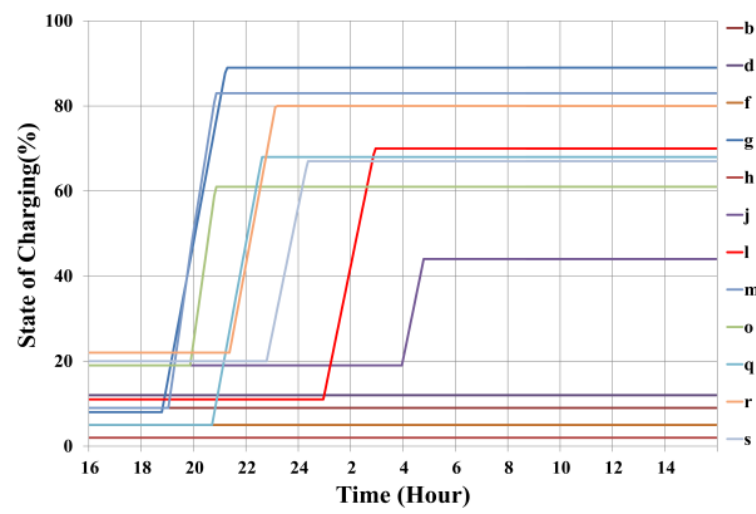

(c)

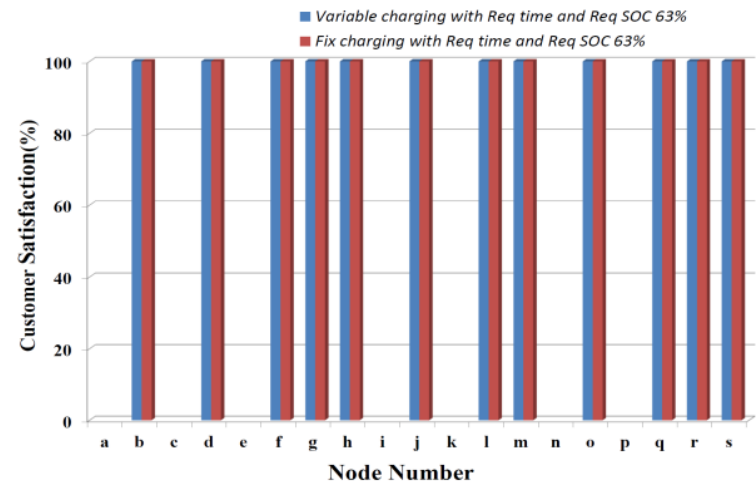

(e)

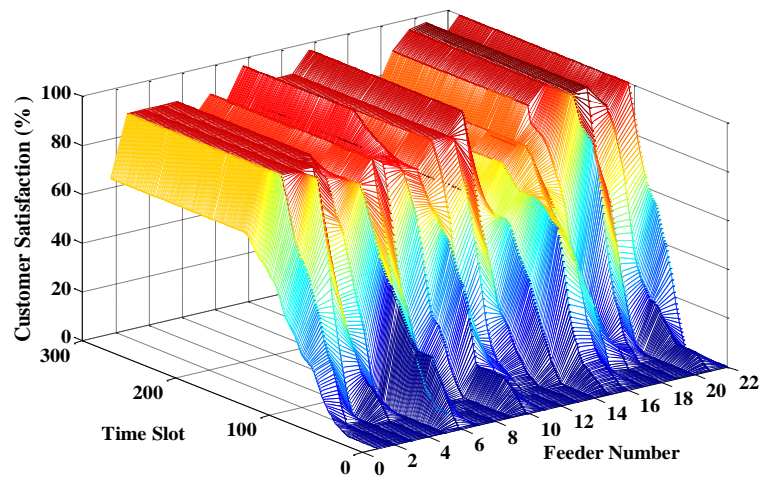

(g)

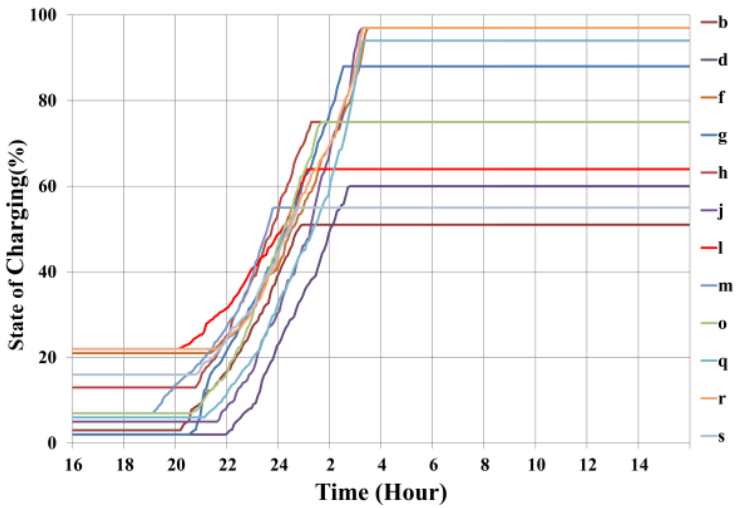

(b)

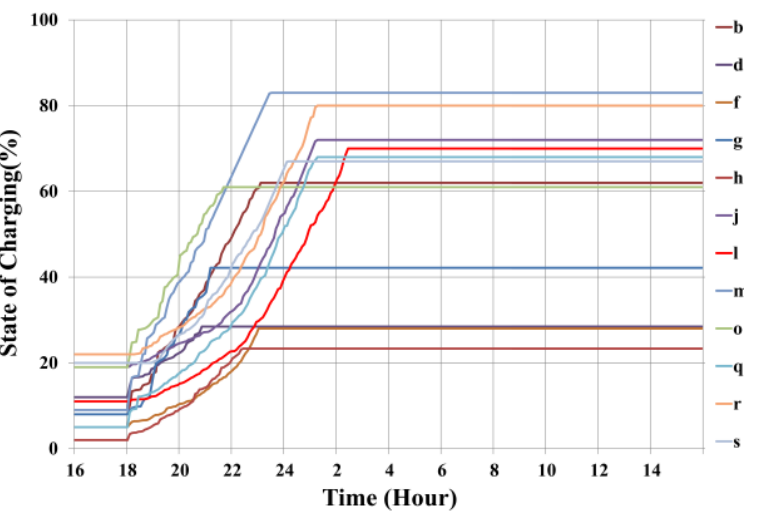

(d)

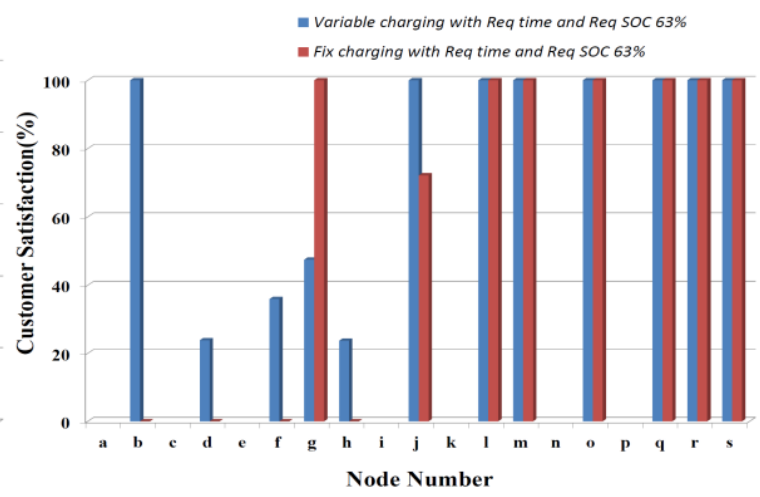

(f)

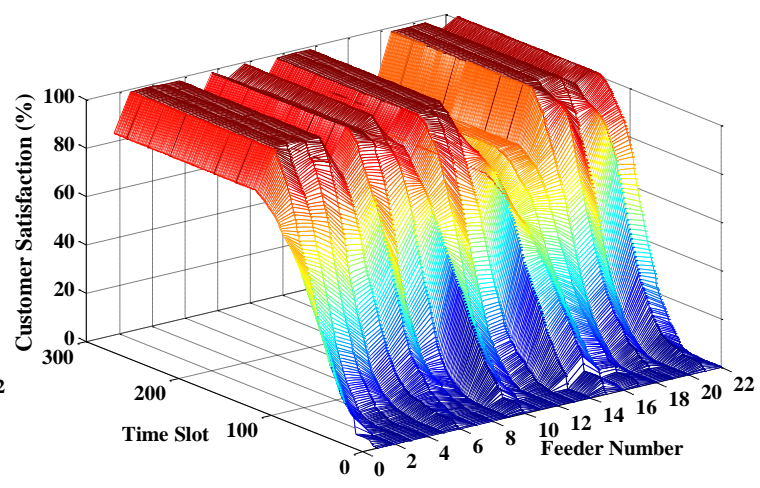

(h) 
- Proposing a CAPSO based algorithm for variable online PEV charging coordination.

- Precise modeling of battery and charger for each PEV considering their efficiency curves.

- Formulating the variable PEVs charging coordination problem to optimize customer satisfaction index.

- Modeling of customer behavior and their driving patterns as well as required SOC in a desired charging time.

- Comparing the performance of variable and fix charging coordination. 